\title{
Prevalence of tick-borne pathogens in questing Ixodes ricinus ticks in urban and suburban areas of Switzerland
}

\author{
Corinne P. Oechslin ${ }^{1,2,3}$, Daniel Heutschi ${ }^{1}$, Nicole Lenz ${ }^{1,2}$, Werner Tischhauser ${ }^{4}$, Olivier Péter ${ }^{5}$, Olivier Rais ${ }^{6}$, \\ Christian M. Beuret ${ }^{1}$, Stephen L. Leib ${ }^{1,2}$, Sergei Bankoul ${ }^{7}$ and Rahel Ackermann-Gäumann ${ }^{1,8^{*}}$
}

\begin{abstract}
Background: Throughout Europe, Ixodes ricinus transmits numerous pathogens. Its widespread distribution is not limited to rural but also includes urbanized areas. To date, comprehensive data on pathogen carrier rates of I. ricinus ticks in urban areas of Switzerland is lacking.

Results: Ixodes ricinus ticks sampled at 18 (sub-) urban collection sites throughout Switzerland showed carrier rates of $0 \%$ for tick-borne encephalitis virus, 18.0\% for Borrelia burgdorferi (sensu lato), 2.5\% for Borrelia miyamotoi, 13.5\% for Rickettsia spp., 1.4\% for Anaplasma phagocytophilum, 6.2\% for "Candidatus Neoehrlichia mikurensis", and 0.8\% for Babesia venatorum (Babesia sp., EU1). Site-specific prevalence at collection sites with $n>45$ ticks $(n=9)$ significantly differed for B. burgdorferi (s.I.), Rickettsia spp., and "Ca. N. mikurensis", but were not related to the habitat type. Three hundred fifty eight out of 1078 I. ricinus ticks (33.2\%) tested positive for at least one pathogen. Thereof, about 20\% (71/358) were carrying two or three different potentially disease-causing agents. Using next generation sequencing, we could detect true pathogens, tick symbionts and organisms of environmental or human origin in ten selected samples.

Conclusions: Our data document the presence of pathogens in the (sub-) urban I. ricinus tick population in Switzerland, with carrier rates as high as those in rural regions. Carriage of multiple pathogens was repeatedly observed, demonstrating the risk of acquiring multiple infections as a consequence of a tick bite.
\end{abstract}

Keywords: Ixodes ricinus, Borrelia, Rickettsia, Anaplasma, "Candidatus Neoehrlichia mikurensis", Babesia, Tick-borne encephalitis virus, "Candidatus Midichloria mitochondrii", Urban, NGS

\section{Background}

Ixodes ricinus is the most frequent tick species throughout Europe. Its life-cycle proceeds through three developmental stages, larvae hatching from eggs, nymphs, and adult males or females. Ixodes ricinus may act as a parasite on more than 200 different species, including humans. It serves as a vector for numerous human and animal pathogens of bacterial, viral, or protozoic origin $[1,2]$.

\footnotetext{
* Correspondence: rahel.ackermann@babs.admin.ch

'Spiez Laboratory, Federal Office for Civil Protection, Austrasse, Spiez, Switzerland

${ }^{8}$ Swiss National Reference Centre for tick-transmitted diseases, Spiez, Switzerland

Full list of author information is available at the end of the article
}

Tick-borne encephalitis virus (TBEV) causes disease of variable severity, ranging from subclinical infections to severe disease with neurological involvement and potentially fatal outcome. TBEV is taxonomically classified into European, Siberian and Far Eastern subtypes; I. ricinus is the principal vector for the European subtype of the virus [3, 4]. Multiple species of rodents, insectivores and carnivores serve as reservoir hosts of TBEV [5, 6]. Although the virus is transmitted transovarially in I. ricinus ticks, this transmission is not effective enough in sustaining viral circulation in nature [7]. Co-feeding is essential for TBEV maintenance in natural foci [8]. Mean prevalence in endemic regions ranges from $<0.1$ to $5 \%$ in Europe and 4 to $39 \%$ in Asia [9]. In Switzerland, 38/165 rural sites screened for the 
presence of TBEV in I. ricinus ticks were shown to harbor natural foci, with a mean virus prevalence of $0.46 \%$ [10].

Lyme borreliosis is a multisystemic disease that causes local infections in the skin or disseminates to various tissues, including joints, the central nervous system and the heart [11]. It is prevalent in North America, Europe, parts of North Africa, and northern Asia. Within the $B$. burgdorferi (sensu lato) complex, B. afzelii, B. burgdorferi and $B$. garinii are confirmed agents of localized, disseminated and chronic manifestations of Lyme borreliosis, whereas B. spielmanii, B. bissettii and B. valaisiana have only been associated with few cases of Lyme borreliosis [11]. Ixodes ricinus is the predominant vector of $B$. burgdorferi (s.l.) in Europe and small mammals and ground-foraging birds serve as reservoir hosts $[2,12]$. Transovarial transmission of B. burgdorferi (s.l.) in $I$. ricinus is limited [13]. Mean carrier rates are higher in adults $(18.6 \%)$ than in nymphs $(10.1 \%)$, and highest carrier rates are found in central Europe [14]. In questing I. ricinus ticks in (sub-) urban areas of Europe, carrier rates range between 2 and 40.8\% [2]. In rural areas of Switzerland, prevalence ranges between 9 and 40\% for nymphs and from 22 to $47 \%$ in adults [15].

Borrelia miyamotoi may cause a febrile illness possibly presenting as relapsing fever. In immunocompromised patients, it may cause severe disease including meningoencephalitis. The prevalence of B. miyamotoi in I. ricinus ticks in Europe ranges between 0 and $4 \%$. In urban areas of France, a prevalence of $4 \%$ was found, whereas the carrier rate was much lower $(2 / 428)$ in a study conducted in peri-urban and urban areas in southern England [16-20]. Potential reservoir hosts include species of rodents and birds. Different tick species such as Ixodes scapularis and I. ricinus transmit B. miyamotoi transovarially [13, 18, 21-23].

Various Rickettsia species are transmitted by hard ticks in Europe, including $R$. helvetica, $R$. monacensis, $R$. conori and $R$. slovaca implicated in human disease $[2,24,25]$. In Switzerland, $R$. helvetica and $R$. monacensis appear to be of particular importance [26, 27]. Clinical signs of infections with $R$. helvetica include fever, headache and myalgia [28]. Rickettsia monacensis may cause Mediterranean spotted-fever like illness [29]. The prevalence of $R$. helvetica and $R$. monacensis in $I$. ricinus ticks in Europe ranges from 0.5 to $66 \%$, or 0.5 to $34.5 \%$, respectively $[2,30-32]$. In Germany and Slovakia, prevalence of Rickettsia spp. in urban sites ranged between 2.2 and 30.1\% [30, 31, 33, 34]. Ticks serve as both the vector and main reservoir of Rickettsia spp., with transstadial and transovarial transmission being documented [2].

Anaplasma phagocytophilum causes disease in domestic ruminants and horses [35], but may also infect other mammalian species, including humans [36]. Clinical manifestation in humans ranges from mild self-limiting febrile illness to fatal infections [36-39]. Anaplasma phagocytophilum is not transmitted transovarially in $I$. ricinus ticks [40]. Its epidemiological cycles involving mammalian hosts and vectors are complex and comprise different bacterial ecotypes. Carrier rates of I. ricinus in Europe range between $<1 \%$ and about 20\% [36]. At urban sites (Austria, France, Slovakia, Hungary), carrier rates between 0.7 and $8.8 \%$ have been documented [20, 41-44].

"Candidatus Neoehrlichia mikurensis" has been detected in I. ricinus ticks in various European countries, with carrier rates ranging from 0.95 to $23.5 \%$ [42, 45-48]. The reservoir role of several rodent species has been proven [49-52]; transovarial transmission in I. ricinus has not yet been reported [2]. In urban habitats in Slovakia, "Ca. N. mikurensis" has been detected in both I. ricinus ticks and rodents, with prevalence in I. ricinus ranging between $1.0-2.4 \%$ [44, 53]. Only a limited number of severe human disease cases associated with fever, septicemia, malaise and weight loss have been described so far, most often but not exclusively affecting patients with immune deficiency [54-57].

Babesia spp. are best known to cause animal illness. Three species are currently recognized to be involved in human disease in Europe: B. divergens, $B$. venatorum (Babesia sp., EU1), and B. microti, with the bovine parasite $B$. divergens being thought to be responsible for most cases. Clinical signs of babesiosis such as flu-like symptoms or hemolytic anemia are usually but not exclusively limited to immunocompromised patients $[2,58,59]$. Carrier rates of $I$. ricinus ticks in Europe range around 0.2 to $3.0 \%$ for $B$. divergens and 0.4 to $1.3 \%$ for $B$. venatorum $[2,60-62]$. There is evidence for circulation of $B$. divergens and $B$. venatorum in urban areas, given that the respective host species (cattle, ungulates) are present [2, 30, 63]. In Germany, Poland and Slovakia, prevalence in urban habitats ranges from 0.4 to $4.5 \%$ [33, 64, 65]. In rural areas of Switzerland, a prevalence of $1.9 \%$ has been documented [27]. Babesia spp. are generally known to be transmitted both transstadially and transovarially in ticks [66]. However, transovarial transmission could so far not be experimentally demonstrated for B. microti [67].

In Switzerland, several studies on the prevalence of all of the above-described tick-borne pathogens in questing ticks have been performed [10, 27, 68-73]. However, data on the carrier rate of ticks in suburban areas of Switzerland are scarce [60,74], and data on tick-borne pathogens in questing ticks in urban areas were not available to date. In this study, we analyzed 1078 questing I. ricinus ticks sampled at (sub-) urban collection sites throughout Switzerland for the presence of TBEV, B. burgdorferi (s.l.), B. miyamotoi, Rickettsia spp., A. phagocytophilum, "Ca. N. mikurensis" and 
Babesia spp. Additionally, we analyzed ten tick DNA samples using next generation sequencing (NGS), including two positive samples as well as eight randomly selected samples negative for the investigated pathogens. In these latter eight samples, we searched for pathogens potentially missed using specific screening PCRs as well as for members of the tick microbiota.

\section{Methods}

\section{Tick sampling}

A total of 45 (sub-) urban study areas were defined in collaboration with the respective authorities. Within the areas, similar collection sites of at least 100 square meters were chosen. Collection sites in urban parks, river sides, cemeteries or open air swimming pool areas were characterized by the presence of bushes or trees and some kind of litter layer. Within urban forests surrounded by built-up areas and within suburban forests located at the border of the city, collection sites were situated at the edge of deciduous forest with high recreational frequentation. Sampling was performed between 10:00 am and 16:00 pm but not on rainy days. Most collection sites were visited only once in June 2016, with a monthly average temperature of about $16{ }^{\circ} \mathrm{C}$. At 11 collection sites in the city of Zürich, ticks were collected throughout the year at 6 different time points (June, July, September and November 2015, April and May 2016). These sites were selected to be visited several times in the framework of another study, where the presence of ticks was related to the number of registered tick bites (unpublished data). Temperature at the collection days for these sites ranged between $13-30{ }^{\circ} \mathrm{C}$, with a relative humidity ranging between $50-85 \%$. Ticks were collected by flagging low vegetation using a terry towel of $1 \mathrm{~m}$ of width and length fixed to a wooden stick. Time invested for tick collection at one collection site ranged between 3 and $5 \mathrm{~h}$. Tick collection was not standardized, since this study did not focus on the tick density in the investigated sites, but rather on the pathogen prevalence found within the analyzed ticks. Collected ticks were kept alive at $4{ }^{\circ} \mathrm{C}$. Following identification based on morphological characteristics $[75,76]$, ticks were individually sorted into collection microtubes (Qiagen, Hilden, Germany) and stored at $-20^{\circ} \mathrm{C}$.

\section{Sample preparation}

Tick samples were homogenized in $600 \mu \mathrm{l}$ of pre-cooled PBS using the TissueLyser system (Qiagen, Hilden, Germany). After a short centrifugation step, $400 \mu \mathrm{l}$ of the supernatant were transferred to a Deepwell plate (Eppendorf, Hamburg, Germany), $60 \mu \mathrm{l}$ of glycerin were added per well and the plates stored at $-80{ }^{\circ} \mathrm{C}$ for further use. $100 \mu \mathrm{l}$ of the supernatant were used for nucleic acid extraction.

\section{Nucleic acid (NA) extraction}

$100 \mu \mathrm{l}$ of tick homogenate supernatant were lysed in 400 $\mu \mathrm{l}$ of AVL buffer supplemented with InhibitEX Tablets (Qiagen, Hilden, Germany) in a 96-well MagNA Pure processing cartridge (Roche, Penzberg, Germany). NA extraction was performed with the MagNA Pure 96 instrument and the MagNA Pure 96 DNA and Viral NA Large Volume kit, using the Pathogen Universal LV 2.0 protocol, a sample volume of $500 \mu \mathrm{l}$ and an elution volume of $100 \mu \mathrm{l}$. NA quality was randomly controlled using the Agilent 2100 Bioanalyzer system with the Agilent High Sensitivity DNA Kit (Agilent Technologies Inc., Santa Clara, California, USA).

\section{Real-time (reverse transcription-) PCR}

The real-time (RT-PCR) systems used for screening the tick samples on the presence of TBEV, Borrelia spp., $B$. miyamotoi, Rickettsia spp., A. phagocytophilum, "Ca. N. mikurensis" and Babesia spp. are summarized in Table 1. For Rickettsia spp. and Babesia spp., two screening systems were used.

\section{Sanger (capillary electrophoresis) sequencing}

Samples positive for Borrelia spp., Rickettsia spp. and Babesia spp. were further examined by sequence analyses to identify the respective species. A subset of samples, where tick species identification based on morphological characteristics was unclear (mainly larvae, $n=75$ ), were analyzed by Sanger sequencing as well. Nested PCR amplifications and sequence analyses were done by Microsynth (Balgach, Switzerland) using the primers and annealing temperatures summarized in Table 2. First-step PCR reactions were run with $2.5 \mu \mathrm{l}$ of template DNA in a total volume of $12.5 \mu \mathrm{l}$ including $0.5 \mu \mathrm{M}$ of each primer, $200 \mu \mathrm{M}$ dNTPs, $1.5 \mathrm{mM} \mathrm{MgCl} 2$ and $0.02 \mathrm{U} / \mu \mathrm{l}$ KAPA2G Robust polymerase (Axon Lab, Baden, Switzerland). Fourty cycles were run for each PCR (denaturation: 20 s, $95{ }^{\circ} \mathrm{C}$; annealing: locusspecific temperatures, $20 \mathrm{~s}$; elongation: $100 \mathrm{~s}, 72{ }^{\circ} \mathrm{C}$; final elongation step: $45 \mathrm{~s}, 72{ }^{\circ} \mathrm{C}$ ). First-step PCR products were diluted 1:100 for the second-step PCRs, which were run under the same PCR conditions as described for the first-step PCR using the nested primers described in Table 2. Successful amplification was verified on a $1.5 \%$ agarose gel. PCR products were purified and uni-directionally Sanger sequenced. Sequences were quality-trimmed and manually edited, then locus-wise subjected to alignment and phylogenetic analysis using the Phylogeny.fr website [77]. Species identification was done using BLASTn comparison (NCBI nucleotide database) [78, 79]. The sequences obtained from this study have been deposited in the GenBank database (MF121944-MF121977). 


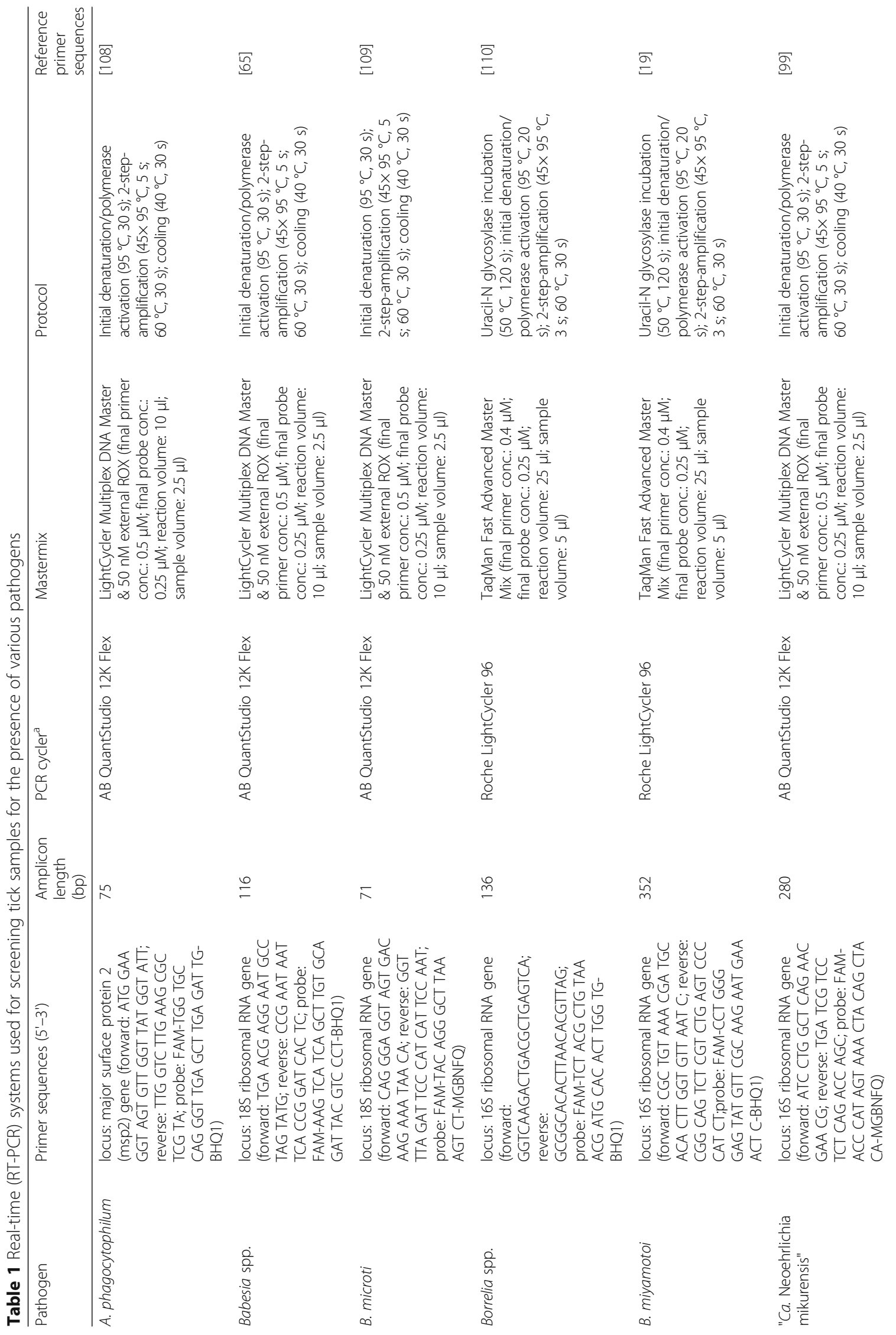




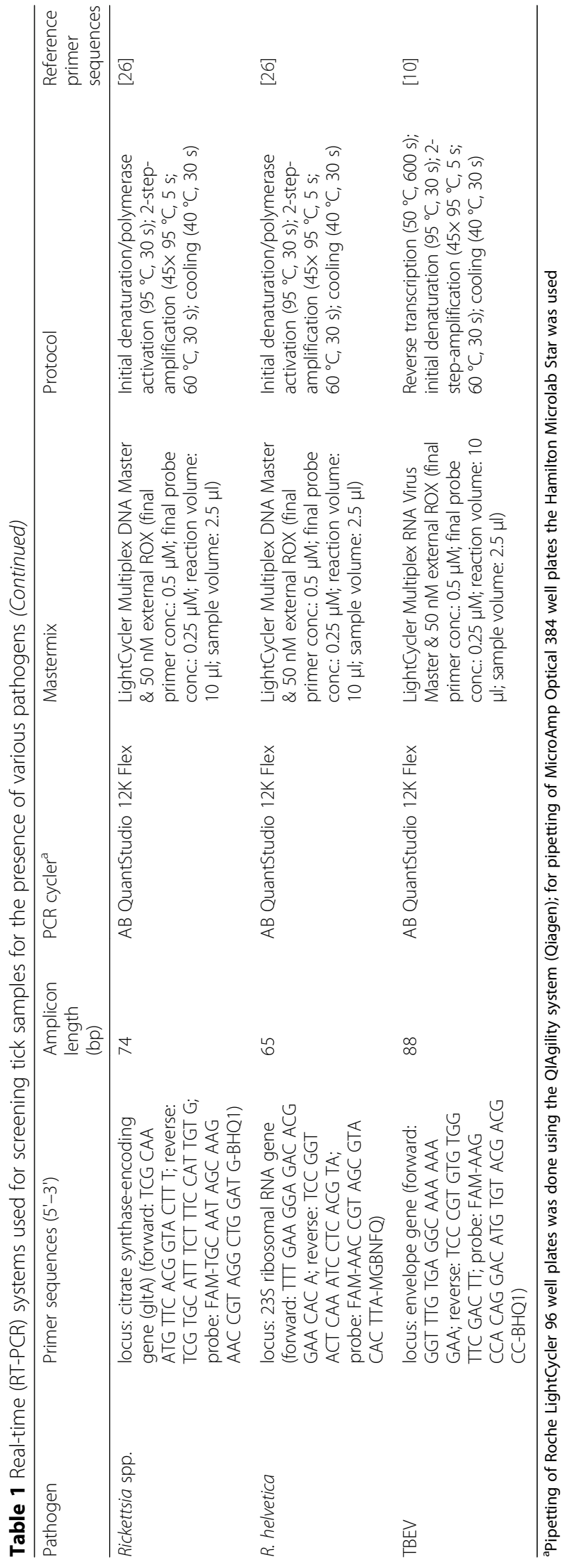


Table 2 Primer sequences and annealing temperatures of Sanger sequencing reactions

\begin{tabular}{|c|c|c|c|c|c|}
\hline Species & Primer sequences $\left(5^{\prime}-3^{\prime}\right)$ & $\begin{array}{l}\text { Amplicon } \\
\text { length (bp) }\end{array}$ & $\begin{array}{l}\text { Amplicon position } \\
\text { (reference sequence) }\end{array}$ & $\begin{array}{l}\text { Annealing } \\
T\left({ }^{\circ} \mathrm{C}\right)\end{array}$ & Reference \\
\hline \multicolumn{6}{|l|}{ Fist-step PCR } \\
\hline Borrelia spp. & $\begin{array}{l}\text { locus: 5S-23S intergenic spacer (forward: GAG TTC } \\
\text { GCG GGA GAG TAG GT ATT; reverse: TCA GGG } \\
\text { TAC TTA GAT GGT TCA CTT CC }\end{array}$ & 420 & 3063-3483 (JX564636.1) & 64 & [111] \\
\hline Babesia spp. & $\begin{array}{l}\text { locus: } 18 \text { ribosomal RNA gene (forward: GTC TTG } \\
\text { TAA TTG GAA TGA TGG; reverse: TAG TIT ATG } \\
\text { GTT AGG ACT ACG) }\end{array}$ & 489 & 466-955 (AJ439713) & 58 & [112] \\
\hline Rickettsia spp. & $\begin{array}{l}\text { locus: } 23 S-5 \text { S intergenic spacer (forward: GAT AGG } \\
\text { TCR GRT GTG GAA GCA C; reverse: TCG GGA YGG } \\
\text { GAT CGT GTG TIT C) }\end{array}$ & 388 & 1-388 (AY125012) & 68 & [113] \\
\hline Ticks & $\begin{array}{l}\text { locus: cytochrome c oxidase (forward: ACW AAY } \\
\text { CAY AAA GAC ATT GGA AC; reverse: WGG ATG } \\
\text { CCC RAA RAA TCA AAA T) }\end{array}$ & 704 & 1242-1946 (KF197132) & 48 & [114] \\
\hline \multicolumn{6}{|l|}{ Second-step PCR } \\
\hline Borrelia spp. & $\begin{array}{l}\text { locus: } 235-5 S \text { intergenic spacer (forward: GGA } \\
\text { GAG TAG GTT ATT GCC AG; reverse: GGT TCA } \\
\text { CTT CCC CTG GTA TC) }\end{array}$ & 396 & 3073-3468 (JX56436.1) & 64 & - \\
\hline Babesia spp. & $\begin{array}{l}\text { locus: } 185 \text { ribosomal RNA gene (forward: GTA } \\
\text { ATT GGA ATG ATG GTG AC; reverse: GTT AGG } \\
\text { ACT ACG ACG GAA TC) }\end{array}$ & 475 & 471-946 (AJ439713) & 58 & - \\
\hline Rickettsia spp. & $\begin{array}{l}\text { locus: } 235-5 S \text { intergenic spacer (forward: CAG } \\
\text { TAA TGT GTG TAG CTA AC; reverse: ATC GTG } \\
\text { TGT TTC ACT CAT GC) }\end{array}$ & 356 & 22-378 (AY125012) & 58 & - \\
\hline Ticks & $\begin{array}{l}\text { locus: cytochrome c oxidase (forward: AYC AYA } \\
\text { AAG ACA TTG GAA CWA T; reverse: GCC CRA } \\
\text { ARA ATC AAA ATA RAT G) }\end{array}$ & 686 & 1245-1933 (KF197132) & 48 & - \\
\hline
\end{tabular}

\section{Reverse line blot (RLB)}

Samples positive for Borrelia spp. yielding mixed sequences in Sanger sequencing, indicating the presence of multiple Borrelia species, were additionally analyzed using RLB as described before [80-83]. The variable spacer region between 2 repeated copies of the $23 \mathrm{~S}$ and $5 \mathrm{~S}$ ribosomal genes was amplified by PCR with primers 23S-Bor and B-5S-Bor [80]. For species identification, PCR products were hybridized to 15 oligonucleotide probes [81-83] and blotted on an active Biodyne $\mathrm{C}$ membrane using a Miniblotter 45 (Immunetics, Boston, Massachusetts, USA). Hybridization was visualized by incubating the membrane with enhanced chemiluminescence detection liquid and by exposing the membrane to an X-ray film.

\section{NGS and bioinformatics pipeline}

Eight randomly chosen samples negative in all pathogen screening PCRs (samples 3-8), 1 sample positive in Borrelia spp., $R$. helvetica and $A$. phagocytophilum screening PCRs (sample 1), and 1 sample positive for $R$. helvetica (sample 2) were subjected to NGS. With these analyses, we aimed to (i) demonstrate the congruency of detecting known pathogens using NGS and real-time screening PCR, (ii) investigate whether some pathogens may potentially be missed using specific screening PCR, and (iii) analyze the microbiota of our I. ricinus tick samples. The NGS workflow as well as the bioinformatics pipeline used for data evaluation are described in Additional file 1.

\section{Pathogen prevalence}

Individual carrier rates were assessed for collection sites with more than 45 collected ticks $(n=9)$. Furthermore, since the carrier rates did not significantly differ between habitat types (see statistical analysis), overall prevalence was calculated. Larvae were only included for calculation when the respective pathogen is transmitted transovarially (B. miyamotoi, Rickettsia spp., Babesia spp.). As the samples size for the different dates and collection sites was small, a statistical evaluation of pathogen prevalence in dependence of collection dates was not possible.

\section{Statistical analysis}

The stats package of the $\mathrm{R}$ software (version 3.3.2) [84] was used to assess differences in pathogen prevalence between collection sites, habitats (cemetery, urban park, urban forest, suburban forest), developmental stages (larvae, nymphs, adults) and gender (male, female). A generalized linear model (GLM) using the logit link function under the binomial distribution was applied. 
Chi-square tests were performed to assess significance levels. Pathogen prevalence with respect to developmental stages were analyzed using collection site as an interacting explanatory variable and the Chi-square test was used to compare the main (Stage/Gender"Collection site) model to the reduced model (only collection site). For all analyses, larvae were only included when the respective pathogen is transmitted transovarially (B. miyamotoi, Rickettsia spp., Babesia spp.). To evaluate the frequency of certain pathogen combinations, a GLM was applied comparing the prevalence of each pathogen in either mono- or multi- $(\geq 2)$ infected ticks. Since only $R$. helvetica were found in larvae, developmental stage was included as an interacting explanatory variable. Finally, Chi-square significance testing was used to compare total count of collected ticks according to season (spring or fall) for sites where multiple collections had been performed. For this purpose a GLM under the Poisson distribution was applied using collection site as an interacting explanatory variable. After applying the Bonferroni correction for multiple comparisons $(n=5)$, a $P$-value $<0.05$ was regarded as significant.

\section{Results}

\section{Tick sampling and species identification}

A total of 1,079 ixodid ticks (66 larvae, 740 nymphs, 138 adult males and 135 adult females) were collected at 18 collection sites (Fig. 1, Table 3); at 27 sites, no ticks were found. Tick collection was not standardized with respect to collection time and area, with exception of the sites where flagging was done at multiple time points. Therefore, the collection success in this study must not be equated to questing tick density in the sampling regions. At the collection sites where flagging was done at six different time points, collection was significantly more successful in spring (June 2015, April and May 2016) than in summer or fall (July, September, November 2015) (Chi-square test with Bonferroni correction, $\chi^{2}=$ 52.62, $d f=2, P<0.0001$ ) (Table 4). Except one female Ixodes hexagonus, all ticks were identified as I. ricinus based on morphological criteria or Sanger sequencing results of the cytochrome $c$ oxidase locus.

\section{Pathogen prevalence}

Table 5 summarizes the number of positive I. ricinus ticks found per collection site. Pathogen prevalence was not significantly different between collection sites belonging to different habitat types (i.e. cemetery, urban park, urban forest, suburban forest) ( $P$-values with Chisquare test using Bonferroni correction $>0.1$ for $B$. burgdorferi (s.l.), B. miyamotoi, A. phagocytophilum and $B$. venatorum, $>0.05$ for "Ca. N. mikurensis"). We therefore calculated overall prevalence, which was $0 \%$ for TBEV, $18.0 \%$ for B. burgdorferi (s.l.) (8.2\% for B. afzelii, $1.3 \%$ for B. burgdorferi (sensu stricto), 2.8\% for B. garinii, $0.9 \%$ for B. valaisiana, $2.3 \%$ for multiple Borrelia spp., see below), $2.5 \%$ for B. miyamotoi, $13.5 \%$ for Rickettsia spp. (13.2\% for $R$. helvetica, $0.3 \%$ for $R$. monacensis), $1.4 \%$ for A. phagocytophilum, $6.2 \%$ for "Ca. N. mikurensis" and $0.8 \%$ for $B$. venatorum. In addition to overall

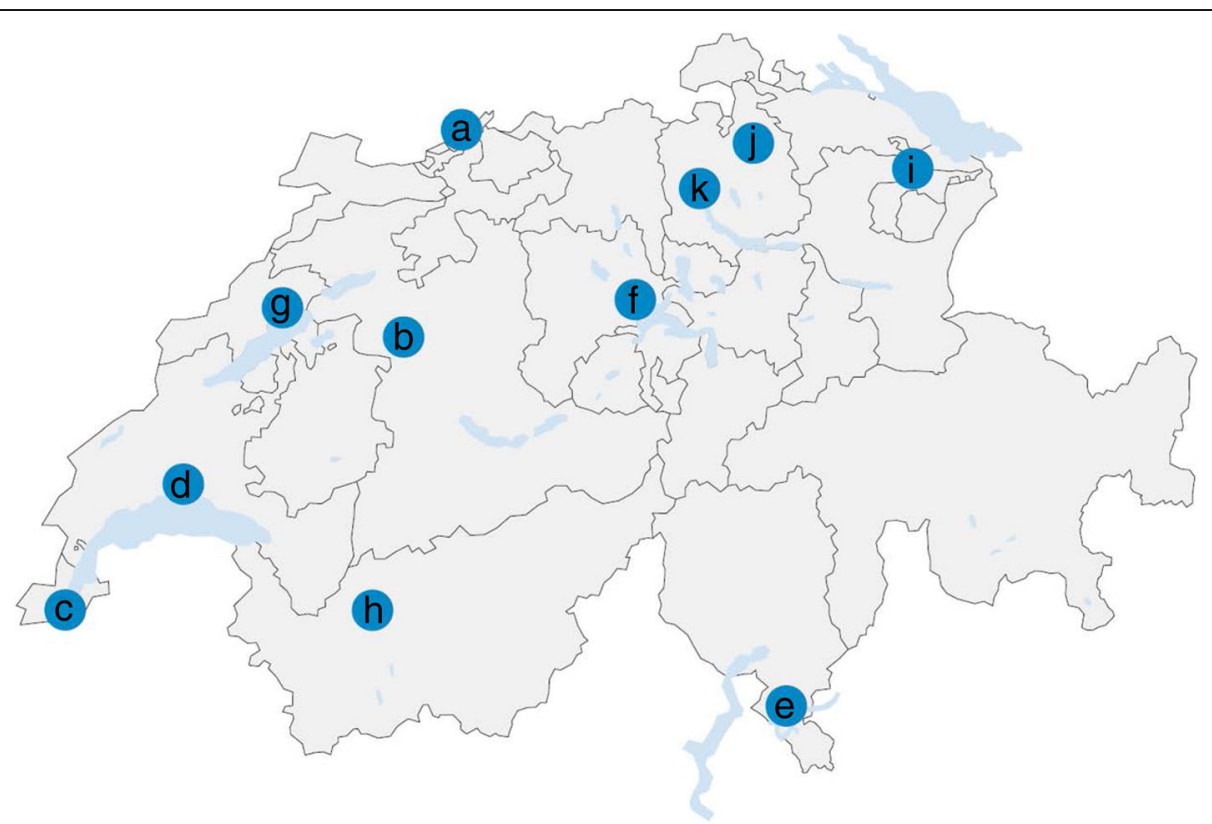

Fig. 1 Urban areas in Switzerland analyzed for the presence of pathogens in questing I. ricinus ticks. Tick collection was successful at 18 collection sites: (a) Basel (2 sites), (b) Bern (1 site), (c) Geneva (2 sites), (d) Lausanne (1 site), (e) Lugano (1 site), (f) Luzern (1 site), (g) Neuchâtel (2 sites), (h) Sion (1 site), (i) St. Gallen (1 site), (j) Winterthur (1 site), and (k) Zürich (5 sites) 
Table 3 Overview of ticks collected at the different collection sites

\begin{tabular}{|c|c|c|c|c|c|c|c|c|}
\hline \multicolumn{3}{|c|}{ Collection sites } & \multicolumn{5}{|c|}{ Number of I. ricinus ticks collected ${ }^{a}$} & \multirow[t]{2}{*}{ Non-I. ricinus } \\
\hline City & Name & Description & Total & Larvae & Nymphs & Adult males & Adult females & \\
\hline Basel & Friedhof Hörnli & Cemetery & 246 & 1 & 230 & 6 & 9 & - \\
\hline Basel & Margrethenpark & Urban park & 83 & - & 66 & 10 & 7 & - \\
\hline Bern & Allmend & Urban park & 123 & - & 9 & 53 & 61 & - \\
\hline Bern & Gaswerkareal & Urban park & - & - & - & - & - & - \\
\hline Bern & Monbijoupark & Urban park & - & - & - & - & - & - \\
\hline Chur & Schwimmbad obere Au & Open air swimming pool & - & - & - & - & - & - \\
\hline Chur & Spielplatz Böschengut & Urban park & - & - & - & - & - & - \\
\hline Geneva & Bois de la Bâtie & Urban forest & - & - & - & - & - & - \\
\hline Geneva & Bois des frères & Suburban forest & 135 & 1 & 98 & 18 & 18 & - \\
\hline Geneva & Parc des Croppettes & Urban park & 2 & - & 2 & - & - & - \\
\hline Lausanne & Parc de la Gottéttaz & Urban forest & - & - & - & - & - & - \\
\hline Lausanne & Parc de l'Hermitage & Urban park & 103 & 1 & 42 & 32 & 28 & - \\
\hline Lugano & Gentilino Pambio & Urban forest & - & - & - & - & - & - \\
\hline Lugano & Parco San Michele & Urban park & 1 & - & 1 & - & - & - \\
\hline Lugano & Parco Del Tassino & Urban park & - & - & - & - & - & - \\
\hline Lugano & Via degli Abeti & Urban forest & - & - & - & - & - & - \\
\hline Luzern & Allmend & Urban park & 2 & - & - & 2 & - & - \\
\hline Luzern & Friedhof Friedental & Cemetery & - & - & - & - & - & - \\
\hline Luzern & Tribschenhorn & Urban park, lake side & - & - & - & - & - & - \\
\hline Murten & Lindensaal & Urban park & - & - & - & - & - & - \\
\hline Murten & Stadtgraben & Urban park & - & - & - & - & - & - \\
\hline Neuchâtel & Jardin du Prince & Urban forest & 49 & 1 & 44 & - & 4 & 1I. hexagonus female \\
\hline Neuchâtel & Les Cadolles & Suburban forest & 115 & - & 115 & - & - & - \\
\hline Sion & Place de la Planta & Urban park & - & - & - & - & - & - \\
\hline Sion & Place du Scex & Urban park & - & - & - & - & - & - \\
\hline Sion & Vissigen & River side & 1 & - & - & - & 1 & - \\
\hline St. Gallen & Bildweiher & Urban park & 1 & - & - & 1 & - & - \\
\hline St. Gallen & Turnhalle Hodlerstrasse & Urban park & - & - & - & - & - & - \\
\hline Winterthur & Heiligberg & Urban park & 3 & - & 1 & 1 & 1 & - \\
\hline Winterthur & Lindengut & Urban park & - & - & - & - & - & - \\
\hline Winterthur & Rychenbergpark & Urban park & - & - & - & - & - & - \\
\hline Zürich & Chüeweid, site B-1 & Urban park & - & - & - & - & - & - \\
\hline Zürich & Chüeweid, site B-2 & Urban park & - & - & - & - & - & - \\
\hline Zürich & Chüeweid, site B-3 & Urban park & - & - & - & - & - & - \\
\hline Zürich & Friedhof Sihlfeld, sector $C$ & Cemetery & - & - & - & - & - & - \\
\hline Zürich & Friedhof Sihlfeld, sector E & Cemetery & 2 & - & 2 & - & - & - \\
\hline Zürich & Limmatufer & River side & - & - & - & - & - & - \\
\hline Zürich & Rieterpark & Urban park & - & - & - & - & - & - \\
\hline Zürich & Schärrenwiese, site C-1 & Urban park & - & - & - & - & - & - \\
\hline Zürich & Schärrenwiese, site C-2 & Urban park & - & - & - & - & - & - \\
\hline Zürich & Schärrenwiese, site C-3 & Urban park & - & - & - & - & - & - \\
\hline Zürich & Staudenweg & Suburban forest & 5 & - & 3 & 1 & 1 & - \\
\hline
\end{tabular}


Table 3 Overview of ticks collected at the different collection sites (Continued)

\begin{tabular}{|c|c|c|c|c|c|c|c|c|}
\hline \multicolumn{3}{|c|}{ Collection sites } & \multicolumn{5}{|c|}{ Number of I. ricinus ticks collected ${ }^{a}$} & \multirow[t]{2}{*}{ Non-I. ricinus } \\
\hline City & Name & Description & Total & Larvae & Nymphs & Adult males & Adult females & \\
\hline Zürich & Waldrand Waid, Chäferberg & Suburban forest & 47 & 1 & 38 & 6 & 2 & - \\
\hline Zürich & Waidberg Wald & Suburban forest & 143 & 60 & 74 & 7 & 2 & - \\
\hline Zürich & Witikon & Suburban forest & 17 & 1 & 15 & 1 & - & - \\
\hline
\end{tabular}

${ }^{a}$ Collection was done in June 2016 at all collection sites except for Waldrand Waid, Chäferberg and Waidberg Wald

prevalence, we calculated individual carrier rates for collection sites where more than $45 \mathrm{I}$. ricinus ticks had been collected (Table 6). Site-specific carrier rates were was significantly different for B. burgdorferi (s.l.) $\left(\chi^{2}=\right.$ 50.04, $d f=8, P<0.0001)$, Rickettsia spp. $\left(\chi^{2}=56.85\right.$, $d f=8, P<0.0001)$ and "Ca. N. mikurensis" $\left(\chi^{2}=27.86\right.$ $d f=8, P=0.006)$. Pathogen carrier rates did not significantly differ in relevance to tick developmental stages ( $P$-values Chi-square test with Bonferroni correction $>0.08)$. Larvae were exclusively found to be positive for Rickettsia spp. at a percentage of $32.8 \%$.

\section{Samples with multiple pathogens}

Out of 1078 ticks, 358 (33.2\%) were carrying at least one pathogen. 287 ticks (26.6\%) were infected with one, 64 (5.9\%) with two, and seven (0.7\%) with three different pathogens (Figs. 2, 3). For this analysis, we regarded samples with mixed sequences for $B$. burgdorferi (s.l.) in the respective Sanger sequencing reaction as being infected with two different $B$. burgdorferi (s.l.) species. The prevalence of $R$. helvetica in mono-infected ticks was significantly higher than the prevalence in multi-infected ticks (Chi-square test with Bonferroni correction, $\chi^{2}=$ 9.34, $d f=2, P=0.023$ ) (Fig. 2).

\section{RLB for samples with suspected carriage of multiple $B$. burgdorferi (s.l.) species}

Carriage of multiple B. burgdorferi (s.l.) species, indicated by mixed sequences in Sanger sequencing analyses, was found in $23 \mathrm{I}$. ricinus ticks (13 nymphs, four males, six females). Using RLB, however, only five of these samples were found to be positive for $B$. garinii and one sample was found to be positive for B. afzelii. The remaining 17 samples were negative in RLB analysis. Carriage of multiple Borrelia spp. could not be confirmed in any of the samples using RLB.

Table 4 Tick collection success with respect to collection dates for sites with multiple collection attempts

\begin{tabular}{|c|c|c|c|c|c|c|c|}
\hline \multicolumn{2}{|c|}{ Collection sites } & \multicolumn{6}{|c|}{ Number of $I$. ricinus ticks collected } \\
\hline City & Name & $\begin{array}{l}\text { June } \\
2015\end{array}$ & $\begin{array}{l}\text { July } \\
2015\end{array}$ & $\begin{array}{l}\text { September } \\
2015\end{array}$ & $\begin{array}{l}\text { November } \\
2015\end{array}$ & $\begin{array}{l}\text { April } \\
2016\end{array}$ & $\begin{array}{l}\text { May } \\
2016\end{array}$ \\
\hline Zürich & $\begin{array}{l}\text { Waldrand Waid, } \\
\text { Chäferberg }\end{array}$ & 8 & 0 & 6 & 0 & 13 & 20 \\
\hline Zürich & Waidberg Wald & 9 & 21 & 19 & 3 & 42 & 49 \\
\hline
\end{tabular}

NGS

NGS was done with a total of ten samples. Although most of the taxonomically classified reads (Kraken output) were assigned to ixodid ticks (96.5-99.9\%), which is expected in untreated metagenomics samples of eukaryotes, the read numbers of the pathogens previously identified by screening PCRs were clearly distinguishable from the background noise in sample 1 and 2. The reads assigned to $R$. helvetica denoted 76.3 and $82.6 \%$. The reads of sample 1 classified to $A$. phagocytophilum and B. afzelii represented 1.7 and $0.1 \%$, respectively (Fig. 4a). In the remaining eight samples (3-8), no known pathogens could be detected using NGS, which is in agreement with the negative screening PCRs. However, a total of 8 samples (2 adult female, 1 adult male and 5 nymphal ticks) were positive for the tick endosymbiont "Candidatus Midichloria mitochondrii" [85] (Fig. 4a, b). In the adult female ticks, the reads classified to " $\mathrm{Ca}$. M. mitochondrii" represented 74 and $92 \%$ of all bacterial reads. For the male and nymphal ticks, the percentages of bacterial reads classified to this endosymbiont were $0.1 \%$ or $0.5-25 \%$, respectively. In addition, every sample contained variable proportions of organisms known to be residents of soil and water, plant associated bacteria, or normal human microbiota (Fig. 4b)

\section{Discussion}

Throughout Europe, I. ricinus transmits numerous human and animal pathogens. Its widespread distribution includes urbanized areas. Most wildlife species found in urbanized areas in Europe act as maintenance hosts for $I$. ricinus, but may also serve as reservoirs of tick-borne pathogens. In urban sites, these hosts may be rodents, hedgehogs, shrews, birds, lizards, dogs and cats. In periurban areas, larger animals such as foxes, roe deer, and wild boars may act as tick-maintenance and pathogen reservoir hosts. As a consequence of increasing urbanization and the behavior of humans increasingly encroaching on their peri-urban surroundings, the exposition of humans to vector ticks and tick-transmitted pathogens is increasing $[2,86]$. Whereas several studies on the prevalence of various tick-borne pathogens in questing $I$. ricinus ticks have been done in Switzerland so far [10, 27, 68-73], only limited research has focused on ticks collected in suburban areas $[60,74]$. Here, we analyzed questing I. ricinus 
Table 5 Pathogen screening results of I. ricinus ticks from 18 urban collection sites

\begin{tabular}{|c|c|c|c|c|c|c|c|c|c|c|c|c|c|c|c|}
\hline \multicolumn{4}{|c|}{ Collection sites } & \multicolumn{12}{|c|}{ Number of I. ricinus ticks positive for: } \\
\hline City & Name & Description & $n$ & TBEV & B.a. & B.b.(s.s.) & B.g. & B.va. & B.b.(s.l.) & B.m. & R.h. & R.m. & A.p. & B.ve. & N.m. \\
\hline Basel & Friedhof Hörnli & Cemetery & 246 & 0 & 15 & 3 & 5 & 1 & 1 & 8 & 37 & 0 & 3 & 5 & 24 \\
\hline Basel & Margrethenpark & Urban park & 83 & 0 & 4 & 2 & 0 & 0 & 0 & 1 & 20 & 0 & 0 & 1 & 0 \\
\hline Bern & Allmend & Urban park & 123 & 0 & 27 & 0 & 7 & 3 & 7 & 2 & 13 & 0 & 4 & 0 & 12 \\
\hline Geneva & Bois des frères & Suburban forest & 135 & 0 & 5 & 2 & 10 & 2 & 6 & 4 & 7 & 1 & 3 & 0 & 4 \\
\hline Geneva & Parc des Croppettes & Urban park & 2 & 0 & 0 & 0 & 0 & 0 & 0 & 0 & 1 & 0 & 0 & 0 & 0 \\
\hline Lausanne & Parc de l'Hermitage & Urban park & 103 & 0 & 4 & 1 & 2 & 2 & 1 & 2 & 6 & 2 & 1 & 0 & 4 \\
\hline Lugano & Parco San Michele & Urban park & 1 & 0 & 0 & 0 & 0 & 0 & 0 & 0 & 0 & 0 & 0 & 0 & 0 \\
\hline Luzern & Allmend & Urban park & 2 & 0 & 0 & 0 & 0 & 0 & 0 & 0 & 0 & 0 & 0 & 0 & 0 \\
\hline Neuchâtel & Jardin du Prince & Urban forest & 49 & 0 & 2 & 0 & 1 & 1 & 1 & 4 & 2 & 0 & 0 & 0 & 5 \\
\hline Neuchâtel & Les Cadolles & Suburban forest & 115 & 0 & 8 & 0 & 2 & 0 & 6 & 4 & 3 & 0 & 1 & 0 & 4 \\
\hline Sion & Vissigen & River side & 1 & 0 & 0 & 0 & 0 & 0 & 0 & 0 & 0 & 0 & 0 & 0 & 0 \\
\hline St. Gallen & Bildweiher & Urban park & 1 & 0 & 0 & 0 & 0 & 0 & 0 & 0 & 0 & 0 & 0 & 0 & 0 \\
\hline Winterthur & Heiligberg & Urban park & 3 & 0 & 1 & 0 & 0 & 0 & 0 & 0 & 2 & 0 & 0 & 0 & 0 \\
\hline Zürich & Friedhof Sihlfeld, sector E & Cemetery & 2 & 0 & 0 & 0 & 0 & 0 & 0 & 1 & 0 & 0 & 0 & 0 & 0 \\
\hline Zürich & Staudenweg & Suburban forest & 5 & 0 & 2 & 0 & 1 & 0 & 0 & 0 & 2 & 0 & 0 & 0 & 0 \\
\hline Zürich & Waldrand Waid, Chäferberg & Suburban forest & 47 & 0 & 7 & 0 & 0 & 0 & 0 & 0 & 11 & 0 & 0 & 0 & 5 \\
\hline Zürich & Waidberg Wald & Suburban forest & 143 & 0 & 7 & 3 & 0 & 0 & 1 & 1 & 35 & 0 & 1 & 0 & 5 \\
\hline Zürich & Witikon & Suburban forest & 17 & 0 & 1 & 2 & 0 & 0 & 0 & 0 & 3 & 0 & 1 & 0 & 0 \\
\hline
\end{tabular}

Abbreviations: TBEV, Tick-borne encephalitis virus; B.a., Borrelia afzelii; B.b.(s.s.), Borrelia burgdorferi (s.s.); B.g., Borrelia garinii; B.va., Borrelia valaisiana; B.b.(s.l.), Borrelia burgdorferi (s.l.), multiple species; B.m., Borrelia miyamotoi; R.h., Rickettsia helvetica; A.p., Anaplasma phagocytophilum; B.ve., Babesia venatorum (EU1); N.m,

"Candidatus N. mikurensis"

ticks collected at (sub-) urban sites for the presence of various pathogens. Furthermore, we analyzed ten DNA samples using NGS, thereby detecting true pathogens, tick symbionts, as well as organisms of environmental or human origin.

Tick collection was successful in about 40\% (18/45) of the areas flagged during this study. As the focus of our study was the investigation of pathogen prevalence rather than tick density, our tick collection method was not highly standardized. Therefore, the number of collected ticks at the different collection sites does not necessarily reflect the tick density in these areas. As an exception, tick collection effort was approximately standardized at eleven collection sites in the city of

Table 6 Pathogen prevalence in I. ricinus ticks collected at 9 urban or suburban collection sites

\begin{tabular}{|c|c|c|c|c|c|c|c|c|c|c|}
\hline \multicolumn{4}{|c|}{ Collection sites } & \multicolumn{7}{|c|}{ Prevalence (\%) } \\
\hline City & Name & Description & $n^{\mathrm{b}}$ & TBEV & B.b.(s.l. $)^{a}$ & B.m. & R.spp. $^{a}$ & A.p. & B.v. & N.m. \\
\hline Basel & Friedhof Hörnli & Cemetery & 245 (246) & 0 & 17.1 & 3.3 & 15.0 & 1.2 & 2.0 & 9.8 \\
\hline Basel & Margrethenpark & Urban park & 83 & 0 & 7.2 & 1.2 & 24.1 & 0 & 1.2 & 0 \\
\hline Bern & Allmend & Urban park & 123 & 0 & 35.8 & 1.6 & 10.6 & 3.3 & 0 & 9.8 \\
\hline Geneva & Bois des frères & Suburban forest & $134(135)$ & 0 & 18.5 & 3.0 & 5.9 & 2.2 & 0 & 3.0 \\
\hline Lausanne & Parc de I'Hermitage & Urban park & $102(103)$ & 0 & 9.7 & 1.9 & 6.7 & 1.0 & 0 & 3.9 \\
\hline Neuchâtel & Jardin du Prince & Urban forest & $48(49)$ & 0 & 10.2 & 8.2 & 4.1 & 0 & 0 & 10.2 \\
\hline Neuchâtel & Les Cadolles & Suburban forest & 115 & 0 & 13.9 & 3.5 & 2.6 & 0.9 & 0 & 3.5 \\
\hline Zürich & Waldrand Waid, Chäferberg & Suburban forest & $46(47)$ & 0 & 14.9 & 0 & 23.4 & 0 & 0 & 10.6 \\
\hline Zürich & Waidberg Wald & Suburban forest & $83(143)$ & 0 & 14.5 & 0.7 & 24.5 & 1.2 & 0 & 6.0 \\
\hline
\end{tabular}

Abbreviations: TBEV, Tick-borne encephalitis virus; B.a., Borrelia burgdorferi (s.l.); B.m., Borrelia miyamotoi; R. spp., Rickettsia spp.; A.p., Anaplasma phagocytophilum; B.ve., Babesia venatorum (EU1); N.m, "Candidatus N. mikurensis"

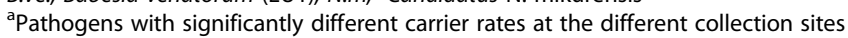

${ }^{\mathrm{b}}$ The number in parentheses represents the sample size including larvae. Larvae were only included for the calculation of prevalence for pathogens being transmitted transovarially: B. miyamotoi, Rickettsia spp., B. venatorum (EU1) 


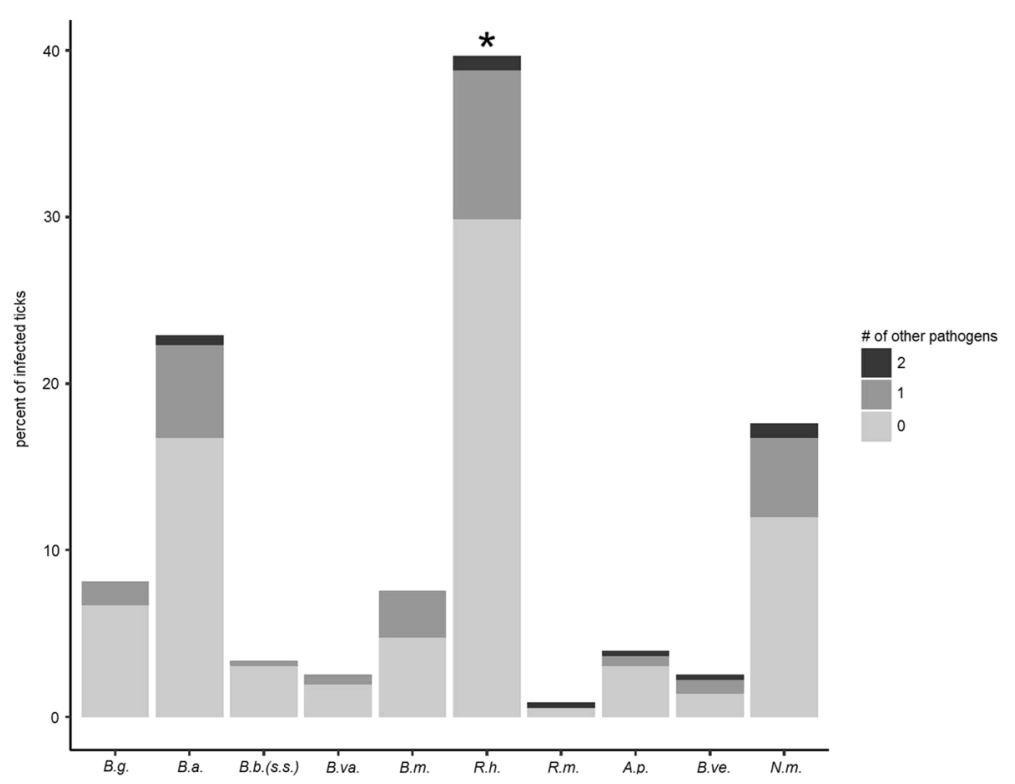

Fig. 2 Number of ticks positive for different tick-borne pathogens. The overall height of the bars represents the percentage of infected ticks tested positive for the respective pathogen. The proportions at which the pathogens were detected alone or in combination with one or two others are shown in light gray, dark gray, and black, respectively. Abbreviations: B.g., B. garinii; B.a., B. afzelii; B.b.(s.s.), B. burgdorferi (sensu stricto); B.va., B. valaisiana; B.m., B. miyamotoi; R.h., R. helvetica; R.m., R. monacensis; A.p., A. phagocytophilum; B.ve., B. venatorum (Babesia sp., EU1); N.m., "Candidatus N. mikurensis"; B.b.(s.l.), two (or more) different B. burgdorferi (sensu lato) species. R. helvetica was significantly more often detected alone than in association with another pathogen (GLM with developmental stage as a dependent variable; Chi-square test with Bonferroni correction, $P=0.023$ )

Zürich, where tick sampling was done throughout the year at six different time points (June, July, September and November 2015, April and May 2016) (Table 4). When comparing collection success between collections done in spring (April, May, June) to collections done in summer or fall (July, September, November), we found that collection was significantly more successful in spring than in summer or fall $(P<0.0001)$. These findings are in agreement with the results of a study focusing on seasonality of $I$. ricinus ticks on the vegetation in two regions in Switzerland, where a significant decline of questing activity in June was observed [87]. Also, they are explained by the conditions for tick activity (temperature and humidity), which are more likely fulfilled in spring than in summer or fall.

TBEV-infected ticks are distributed in a patchy manner in so-called natural foci. In Europe, within these foci, carriage rates of $I$. ricinus ticks range between $<0.1 \%$ and 5\% [9] (Switzerland: 0.46\% [10]). In the present study focusing on urban areas, we could not detect any TBEV-positive I. ricinus ticks. However, given the low expected carrier rates, the sample sizes per collection site are too small to allow for a reliable estimation of TBEV prevalence. Accordingly, the prevalence of $0 \%$ has to be interpreted with caution, and more extensive studies are needed to precisely estimate the carrier rate of (sub-) urban I. ricinus ticks with TBEV in Switzerland.
In studies focussing on urban or peri-urban regions of other European countries (Germany, Poland), TBEV has been detected with carrier rates of $0.31 \%$ or $0.1 \%$, respectively $[88,89]$. On the other hand, other authors estimate the risk for contracting TBE in urban areas to be low [4].

Four different species belonging to the B. burgdorferi (s.l.) complex were detected in questing $I$. ricinus ticks in our study: B. afzelii (8.2\% of ticks), B. garinii (2.8\%), B. burgdorferi (s.s.) (1.3\%) and B. valaisiana (0.9\%). All of them are confirmed agents of Lyme borreliosis [11] and have already been detected in I. ricinus ticks in other studies in Switzerland [15, 27]. In agreement with previous observations, we found that $B$. afzelii and $B$. garinii are the most prominent species, and that adult ticks are more often infected with B. burgdorferi (s.l.) than nymphs. The latter observation is explained by the fact that adult ticks had two blood meals with the possibility of acquiring B. burgdorferi (s.l.), whereas nymphs only had one [14]. The overall prevalence of B. burgdorferi (s.l.) in the present study was $18.0 \%(11.7 \%$ for nymphs, $25 \%$ for adults), with site-specific prevalence being significantly variable $(7.2-35.8 \%, P<0.0001)$. These observations are in agreement with a study realized in rural areas of Switzerland, where carriage rates ranged between $9-40 \%$ for nymphs and from 22 to $47 \%$ in adults [15]. The overall prevalence of B. burgdorferi 


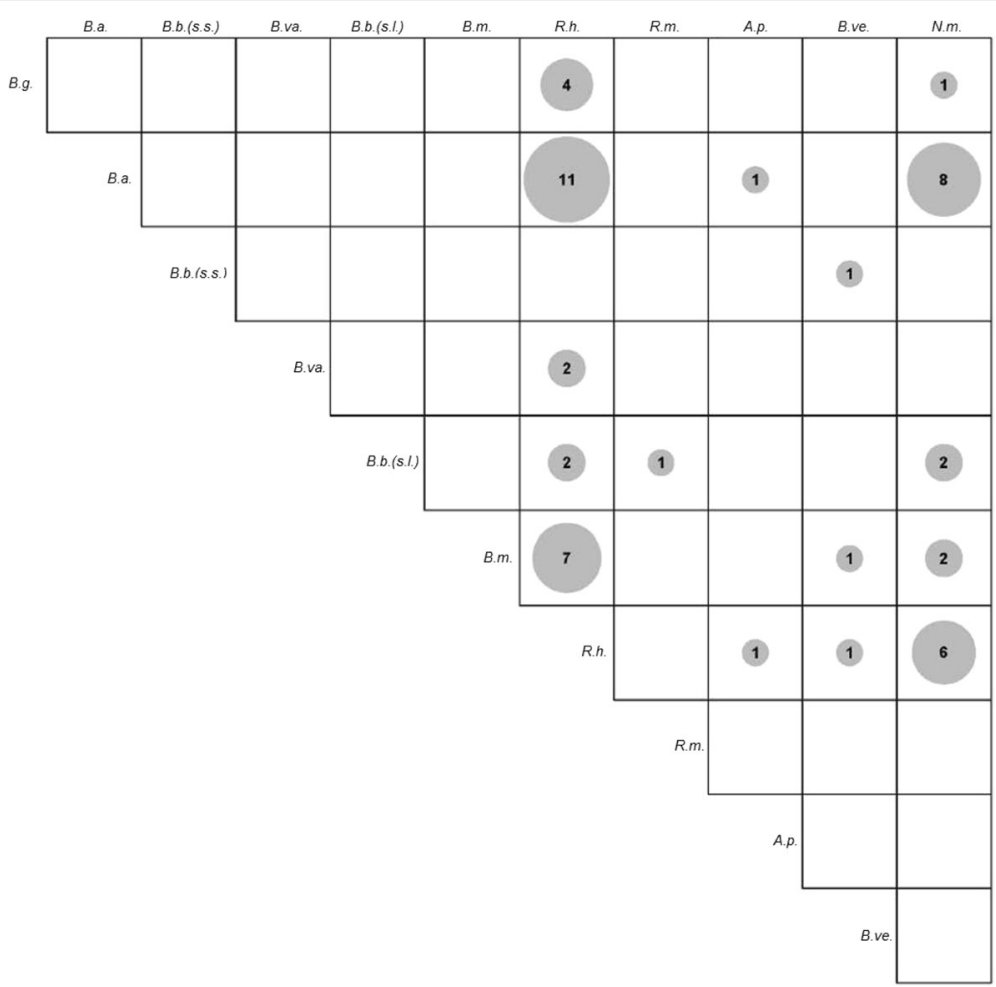

Fig. 3 Correlation-plot showing the pathogen combinations observed in urban I. ricinus ticks in Switzerland. The more frequent a pathogen combination, the bigger the respective circle in the plot. In addition, the absolute counts of ticks with the particular pathogen combination are given in numbers. Abbreviations: B.g., B. garinii; B.a., B. afzelii; B.b.(s.s.), B. burgdorferi (sensu stricto); B.va., B. valaisiana; B.m., B. miyamotoi; R.h., R. helvetica; R.m., R. monacensis; A.p., A. phagocytophilum; B.ve., B. venatorum (Babesia sp., EU1); N.m., "Candidatus N. mikurensis"; B.b.(s.l), two (or more) different $B$. burgdorferi (sensu lato) species, not distinguishable. Other combinations of three different pathogens are not shown in this plot; these were $1 \times$ B. afzelii $+R$. helvetica + A. phagocytophilum and $1 \times$ B. afzelii + B. venatorum (Babesia sp., EU1) + "Ca. N. mikurensis"

(s.l.) in questing I. ricinus ticks in our study is highly comparable to carriage rates found in urban areas of neighboring countries, ranging from 2.4 to $26.6 \%$ in Germany, 10 to $30 \%$ in France, and $10.4 \%$ in Italy [2, 20, 90-92]. In Sanger sequence analyses of the 5S-23S intergenic spacer region, mixed sequences indicating the presence of multiple B. burgdorferi (s.l.) species were obtained for 23 samples (13 nymphs, four males, six females). In confirmatory analyses using RLB, however, only 6 of these samples gave positive results (five $B$.
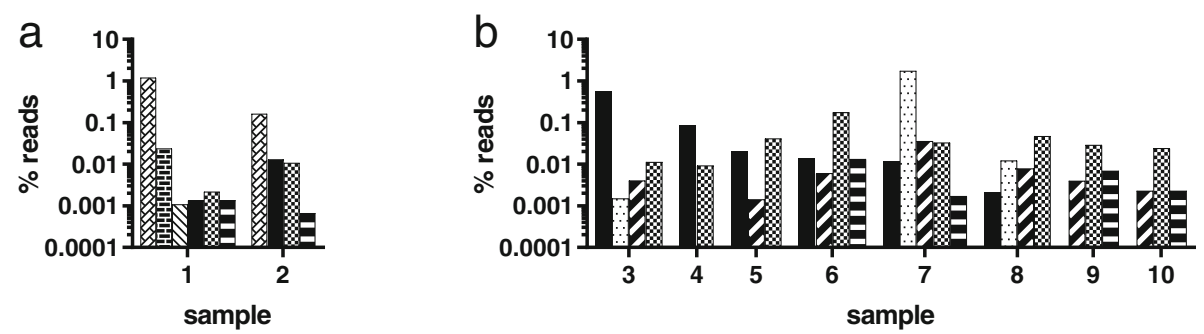

R.h. A.p. MI B.a.

C.M.m. $\quad$ P.spp.

Residents of soil and water

« Commensals, human microbiota

- Plant associated

Fig. 4 NGS results for 10 l. ricinus tick samples. Two samples positive in one or more pathogen screening PCR (a) and 8 samples negative in all screening PCRs $(\mathbf{b})$ were analyzed. Whole genome amplified samples were sequenced on an lon $\mathrm{S}^{\mathrm{T}} \mathrm{M}$, Kraken was used for taxonomic profiling of trimmed reads, and species with low read support were filtered out. Species pathogenic for humans, i.e. R. helvetica (R.h.), A. phagocytophilum (A.p.), B. afzelii (B.a.), as well as the tick endosymbiont "Candidatus Midichloria mitochondrii" (C.M.m.), are represented individually. The remaining species are grouped in Pseudomonas spp. (P.spp.), other residents of soil and water, commensals, human microbiota, and plant associated bacteria. The bars indicate the percentages of reads assigned to the respective species or groups in a logarithmic scale 
garinii, one B. afzelii), and carriage of multiple Borrelia spp. could not be confirmed in any of the samples. Since many of these samples contained only very small amounts of Borrelia DNA with cycle threshold values in screening PCR ranging between 36-40 (data not shown), false-negative results in RLB cannot be excluded. In Sanger sequencing, we were able to raise the sensitivity of the test by adding a second-step PCR using nested primers. Since this was not possible in RLB, we expect this test to have a slightly lower sensitivity, accounting for the discrepancy between RLB and Sanger sequencing results. Therefore, the 23 samples, representing $14.9 \%$ of ticks positive for B. burgdorferi (s.l.), are regarded as being infected with more than one B. burgdorferi (s.l.) species despite the negative RLB results. This proportion is in agreement with the percentage of carriage of multiple B. burgdorferi (s.l.) found previously [14].

Human disease cases caused by B. miyamotoi, usually presenting as febrile illness have been reported in Russia, USA, the Netherlands and Japan [18]. In I. ricinus, the pathogen is found at a prevalence ranging between $0-3.5 \%$ in Europe [17-19]. Borrelia miyamotoi has been shown to be present in I. ricinus ticks in Switzerland in rural areas at a prevalence of about $1 \%$ [27]. In our study $2.5 \%$ of $I$. ricinus ticks $(2.7 \%$ of nymphs, $2.6 \%$ of adult ticks) were infected with $B$. miyamotoi, which is slightly less than the prevalence described for urban I. ricinus ticks in France (4\%) [20], but higher than the number of $B$. miyamotoi positive ticks $(2 / 428)$ reported in a study focusing on urban and peri-urban areas in southern England [16]. Thus, although no disease cases have been reported so far, there is a potential of acquiring such an infection, in urban as well as in rural regions in Switzerland.

Studies investigating I. ricinus ticks collected from vegetation or animals in Switzerland revealed Rickettsia spp. carriage rates of 7.3 to $14 \%$ [21, 26, 93]. In accordance with these results and with the detection of Rickettsia spp. in urban areas in other studies in Germany and Slovakia at carrier rates ranging between $2.2-30.1 \%$ [30, $31,33,34]$, we found $R$. helvetica-positive I. ricinus ticks at a prevalence of $13.2 \%$ in urban areas of Switzerland. We observed significant differences in site-specific carrier rates $(2.6-24.5 \%, P<0.0001)$, which is in agreement with a study in Germany, where prevalence of Rickettsia spp. in I. ricinus ticks ranged between 0-50\% [31]. Unlike the frequent detection of $R$. helvetica in I. ricinus, the documentation of human infection with this agent in different countries, including Switzerland, remains rare [25]. In addition to $R$. helvetica, three samples were found to be positive for $R$. monacensis, which has been detected for the first time in Switzerland in 2009 [26] and is known to be present in I. ricinus ticks in at least
18 European countries [25]. $R$. monacensis has already been discovered in $I$. ricinus ticks in some urban and peri-urban sites in different European countries [2], which is in accordance with our findings.

Anaplasma phagocytophilum has been detected in $I$. ricinus ticks in Europe at a prevalence between $<1 \%$ and about 20\%. In Switzerland, carrier rates between 1.2-2\% have been found [27, 36, 93-97]. Corresponding to these findings we found a carrier rate of $1.4 \%$ in urban I. ricinus ticks. This rate is in agreement with carrier rates found in urban areas of Austria and France (1.0 and 0.7\%, respectively) $[20,41]$, but is rather low compared to the prevalence found in Slovakia or Hungary $(4.5-5.5 \%$ and $8.8 \%$, respectively) [42-44]. In Switzerland, human granulocytic anaplasmosis (HGA) is a rarely diagnosed disease so far. However, considering the repeated detection of the causative agents in ticks and knowing that the seroprevalence in humans bitten by I. ricinus ticks is $17.1 \%$ [98], HGA may increasingly be included in the diagnostic workup of patients with a history of a tick bite. In our study, we merely focused on the detection of A. phagocytophilum, without considering the four different ecotypes. So far, all human cases clustered in ecotype I. The different ecotypes are known to have significantly different host ranges, with ecotype I hosts including numerous urban species $[2,50]$. We would therefore expect many of the A. phagocytophilum isolates detected by real-time PCR in our study to belong to ecotype I. However, the respective analyses have not been done so far.

Neoehrlichiosis is a rare human disease. In Switzerland, a close geographic association of disease cases with $I$. ricinus populations carrying " $\mathrm{Ca}$. N. mikurensis" has been shown for the region of Zürich, where pool carrier rates of $0-8 \%$ were found [99]. In our study we could confirm the presence of "Ca. N. mikurensis" in I. ricinus ticks in the region of Zürich, focusing on (sub-) urban areas. In addition, we could show the pathogen to be present in the cities of Basel, Bern, Geneva, and Neuchâtel, with an overall prevalence of $6.2 \%$. This is a higher rate of carriage compared to findings from urban habitats in Slovakia, where prevalence ranged between $1-2.4 \%$ [44, 53]. Sitespecific carrier rates for "Ca. N. mikurensis significantly differed in our study, ranging from 0 to $10.6 \%(P<0.006)$. This is in agreement with the variation found in the Swiss study in the rural region of Zürich (pool carrier prevalence between $0-8 \%$ ) [99]; variable carriage rates ranging between $1.1-4.5 \%$ were also found in (sub-) urban habitats in a study conducted in Slovakia, the Czech Republic and Austria [42].

Three Babesia species, $B$. divergens, $B$. venatorum and $B$. microti are currently known to cause human disease, and all of them have been found to circulate in urban areas [2, 30, 63]. In 2012 other authors found Babesia spp. to be present in $1.9 \%$ of I. ricinus ticks collected in 
deciduous forests in Western Switzerland. Thereof, 64.3\% were identified as $B$. venatorum and $17.9 \%$ as $B$. divergens [27]. Here, we found a carriage rate of questing urban $I$. ricinus ticks of $0.83 \%$. All positive samples were classified as $B$. venatorum using Sanger sequencing. The prevalence of $0.8 \%$ is in accordance with I. ricinus carrier rates with this parasite in different urban regions in European countries (Germany, Poland and Slovakia), ranging from $0.4 \%$ to $4.5 \%[33,64,65]$. Since $B$. divergens is a bovine parasite, it would only be expected in areas where cattle are found concurrently with I. ricinus ticks [2]. To our knowledge, none of the collection sites of our study represent areas where cattle are present, wherefore the absence of $B$. divergens is plausible. Human babesiosis is a rare but possibly emerging disease in Europe, with about 50 disease cases reported so far $[2,100]$.

Site-specific pathogen prevalence significantly differed for B. burgdorferi (s.l.), Rickettsia spp., and "Ca. N. mikurensis" $(P<0.0001$ for B. burgdorferi (s.l.) and Rickettsia spp., < 0.006 for "Ca. N. mikurensis"). However, these differences were not attributable to the habitat type (i.e. cemetery, urban park, urban forest, suburban forest) ( $P>0.1$ for B. burgdorferi (s.l.), B. miyamotoi, A. phagocytophilum, and B. venatorum, >0.05 for "Ca. N. mikurensis"). When comparing the carrier rates from our study focusing on (sub-) urban areas to carrier rates found in rural areas of Switzerland, no obvious differences were found for most pathogens (prevalence in urban $v s$ rural regions for B. burgdorferi (s.l.) 18.0 vs $9.0-47.0 \%$ [15], for Rickettsia spp. 13.5 vs 7.3-14.0\% [21, 26, 93], for A. phagocytophilum 1.4 vs 1.2-2.0\% [27, 36, 93-97], and for "Ca. N. mikurensis" 6.2 vs $0-8.0 \%$ [99]). For B. miyamotoi, the overall prevalence was $2.5 \%$, which is higher than the prevalence of about $1 \%$ assessed in a study focusing on rural areas of Switzerland. For Babesia spp., the overall prevalence assessed in our study focusing on (sub-) urban areas was lower than the prevalence found in the rural area $(0.8 v s 1.9 \%)$ [21]. This latter finding is in agreement with a study comparing the carrier rates between urban and natural habitats in Slovakia [64] and might be in association with the presence of competent reservoir hosts. Altogether, the potential of pathogen transmission as a consequence of a tick bite is highly comparable between urban and rural areas.

In our study, 358 I. ricinus ticks (33.2\%) were carrying at least one potentially disease-causing agent: 287 (26.6\%) were infected with one, 64 (5.9\%) with two, and seven $(0.7 \%)$ with three different pathogens (Figs. 2, 3). In a study investigating about 270 female $I$. ricinus ticks in the French Ardennes, $45 \%$ of infected ticks were carrying multiple pathogens [101]. In our study involving I. ricinus ticks of all developmental stages, about $80 \%$ of infected ticks were positive for only one pathogen, giving a lower proportion of multiple carriage rates.
Nevertheless, carriage of multiple pathogens by ticks and therewith co-transmission of pathogens to humans might have important consequences with respect to disease severity and treatment [101-104]. The most frequent pathogen combinations in our study were $B$. afzelii $+R$. helvetica $(n=11)$ and B. afzelii $+" C a . \mathrm{N}$. mikurensis" $(n=8)$. Interestingly, the same pathogens have been found to be predominantly involved in coinfections in a study focusing on mixed deciduous forests in the western part of Switzerland. In both, the present and the previous study, $B$. afzelii and $R$. helvetica were the pathogens with the highest prevalence, possibly accounting for the frequent combination of these two bacteria within ticks. B. afzelii and "Ca. N. mikurensis" share common reservoir hosts, which might account for their concurrent detection in individual $I$. ricinus ticks $[27,105,106]$.

Using NGS, we could confirm the presence of all pathogens previously detected by screening PCRs in 2 samples (Fig. 4a, b). In the eight samples negative in all pathogen screening PCRs (samples 3-8), we did not identify any known pathogen using NGS. However, in six of these samples as well as in samples 1 and 2, we could detect the tick endosymbiont "Ca. M. mitochondrii", a member of the order Rickettsiales (Fig. 4a, b). This bacterium is localized in the mitochondria of ovarian cells in I. ricinus female ticks and is transmitted to all offspring. It has been shown to be highly prevalent in I. ricinus ticks, with a mean carrier rate of females of $95 \%$, but a lower prevalence in other developmental stages [85, 107]. Our results agree with these findings with both female, but only five out of seven nymphal $I$. ricinus ticks being positive for " $\mathrm{Ca}$. M. mitochondrii". Also, the number of reads was much higher in female ticks than in male or nymphal ticks, which is in agreement with the described lower bacterial load in male than in female I. ricinus ticks [107].

Besides known pathogens ( $R$. helvetica, A. phagocytophilum, B. afzelii) and tick endosymbionts, we detected various organisms known to be residents of soil and water, plant associated organisms or members of the normal human microbiota in NGS analyses of ten tick samples (Fig. 4a, b). Since we did not wash the surface of the collected ticks prior to sample preparation and nucleic acid extraction, these findings are easily explainable by the presence of these organisms on the exterior of the ticks. While plant, soil and water organisms originate from the collection sites, members of the human microbiota were transmitted to the tick surface during the collection and sorting procedure.

\section{Conclusions}

In this study we documented the presence of $B$. burgdorferi (s.l.), B. miyamotoi, $R$. helvetica, $R$. monacensis, $A$. 
phagocytophilum, "Ca. N. mikurensis" and B. venatorum in the (sub-) urban I. ricinus tick population in Switzerland. The pathogen prevalence was as high as the one in rural regions and thus there is a risk of contracting tick-transmitted diseases in urban areas of Switzerland. Carriage of multiple pathogens was observed in about $20 \%$ of infected I. ricinus ticks, and therefore there is a true risk of acquiring multiple infections as a consequence of a tick bite.

\section{Additional file}

Additional file 1: NGS protocol, bioinformatics pipeline, detailed NGS results and discussion. (DOCX $22 \mathrm{~kb}$ )

\section{Abbreviations}

HGA: human granulocytic anaplasmosis; NGS: next generation sequencing; RLB: reverse line blot; TBE: tick-borne encephalitis; TBEV: tick-borne encephalitis virus

\section{Acknowledgements}

Tick collection was supported by the Swiss Army. We particularly thank Roger Herger for sustaining this study, and all people involved in tick collection. We thank Cornelia Silaghi and Alexander Mathis (Institute of Parasitology, University of Zürich, Zürich, Switzerland) for providing us with DNA from various Babesia spp. as well as a key to morphological tick identification. Many thanks go to Alexis Dumoulin (Institute Central des Hôpitaux du Valais, Sion, Switzerland) for providing us with $R$. helvetica DNA and Reto Lienhard (ADMED Microbiologie, La Chaux-de-Fonds, Switzerland) for providing us with A. phagocytophilum DNA. We thank Christoph Grünig and Patrick Pfistner (Microsynth, Switzerland) for performing Sanger sequencing and sequence data analyses. Finally, many thanks go to Matthias Wittwer, Nicole Liechti, Marc Strasser and Olivier Engler for valuable discussions.

\section{Funding}

The project was funded with in-kind contributions.

\section{Availability of data and materials}

The authors declare that the data underlying analyses on pathogen prevalence and carriage of multiple pathogens are available within the article. Sequences generated using Sanger (capillary electrophoresis) sequencing have been deposited in the GenBank database under the accession numbers MF121944MF121977. Information on NGS analyses are available within supplementary information files. NGS sequencing data are available from the corresponding author upon reasonable request.

\section{Authors' contributions}

SB contributed to organizational support in the collection of ticks by military personnel and discussed the study progress with $\mathrm{DH}$ on a monthly base. $\mathrm{DH}$ organized and assisted in the tick collection done by the Swiss Army and performed the real-time PCR screening of tick samples. CB technically supported the real-time PCR screening. OP and WT collected ticks at different collection sites and different time points, in addition to the ticks collected by the Swiss Army. OR analyzed samples with suspected mixed Borrelia infections using reverse line blot. CO analyzed selected samples using NGS, including all laboratory and data analysis work and contributed in writing the manuscript. NL did the statistical analyses and contributed in writing the manuscript, too. Together with SLL, RAG initiated the project. RAG coordinated the study, morphologically identified all collected ticks and purified nucleic acids from all samples. Also, RAG coordinated the Sanger sequencing with Microsynth, evaluated the data and was a major contributor in writing the manuscript. All authors read and approved the final manuscript.

Ethics approval and consent to participate Not applicable.
Consent for publication

Not applicable.

\section{Competing interests}

The authors declare that they have no competing interests.

\section{Publisher's Note}

Springer Nature remains neutral with regard to jurisdictional claims in published maps and institutional affiliations.

\section{Author details}

${ }^{1}$ Spiez Laboratory, Federal Office for Civil Protection, Austrasse, Spiez, Switzerland. ${ }^{2}$ Institute for Infectious Diseases, University of Bern, Friedbühlstrasse, Bern, Switzerland. ${ }^{3}$ Graduate School for Cellular and Biomedical Sciences, University of Bern, Bern, Switzerland. ${ }^{4}$ ZHAW Life Science and Facility Management, Grüental, Wädenswil, Switzerland. ${ }^{5}$ retired, Infectious Diseases, Central Institute of Valais Hospitals, Sion, Switzerland. ${ }^{6}$ Laboratory of Ecology and Evolution of Parasites, Institute of Biology, University of Neuchâtel, Emile Argand, Neuchâtel, Switzerland. ${ }^{7}$ Medical Services Directorate, Swiss Armed Forces, Ittigen, Switzerland. ${ }^{8}$ Swiss National Reference Centre for tick-transmitted diseases, Spiez, Switzerland.

Received: 13 February 2017 Accepted: 26 October 2017

Published online: 09 November 2017

\section{References}

1. Gray JS. Biology of Ixodes species ticks in relation to tick-borne zoonoses. Wien Klin Wochenschr. 2002;114(13-14):473-8.

2. Rizzoli A, Silaghi C, Obiegala A, Rudolf I, Hubalek Z, Foldvari G, et al. Ixodes ricinus and its transmitted pathogens in urban and peri-urban areas in Europe: New hazards and relevance for public health. Front Public Health. $2014 ; 2(251)$

3. Ecker M, Allison SL, Meixner T, Heinz FX. Sequence analysis and genetic classification of tick-borne encephalitis viruses from Europe and Asia. J Gen Virol. 1999:80(Pt 1):179-85.

4. Lindquist L. Tick-borne encephalitis. In: Tselis ACB, editor. Handbook of Clinical Neurology, vol. 123, 1 edn. Amsterdam, Netherlands: Elsevier; 2014. p. 531-59.

5. Kozuch O, Gresikova M, Nosek J, Lichard M, Sekeyova M. The role of small rodents and hedgehogs in a natural focus of tick-borne encephalitis. Bull World Health Organ. 1967;36:61-6.

6. Suss J. Epidemiology and ecology of TBE relevant to the production of effective vaccines. Vaccine. 2003;1(21):S19-35.

7. Mansfield KL, Johnson N, Phipps LP, Stephenson JR, Fooks AR, Solomon T Tick-borne encephalitis virus - a review of an emerging zoonosis. J Gen Virol. 2009;90(Pt 8):1781-94.

8. Randolph SE. The shifting landscape of tick-borne zoonoses: tick-borne encephalitis and Lyme borreliosis in Europe. Philos Trans R Soc Lond B Biol Sci. 2001;356(1411):1045-56.

9. Suss J. Tick-borne encephalitis 2010: epidemiology, risk areas, and virus strains in Europe and Asia - an overview. Ticks Tick Borne Dis. 2011;2(1):2-15.

10. Gaumann R, Muhlemann K, Strasser M, Beuret CM. High-throughput procedure for tick surveys of tick-borne encephalitis virus and its application in a national surveillance study in Switzerland. Appl Environ Microbiol. 2010;76(13):4241-9.

11. Stanek G, Reiter M. The expanding Lyme Borrelia complex - clinical significance of genomic species? Clin Microbiol Infect. 2011;17(4):487-93.

12. Anderson JF. Mammalian and avian reservoirs for Borrelia burgdorferi. Ann NY Acad Sci. 1988;539:180-91.

13. van Duijvendijk G, Coipan C, Wagemakers A, Fonville M, Ersoz J, Oei A, et al. Larvae of Ixodes ricinus transmit Borrelia afzelii and B. miyamotoi to vertebrate hosts. Parasit Vectors. 2016:9:97.

14. Rauter C, Hartung T. Prevalence of Borrelia burgdorferi (sensu lato) genospecies in Ixodes ricinus ticks in Europe: a meta analysis. Appl Environ Microbiol. 2005;71(11):7203-16.

15. Jouda F, Perret JL, Gern L. Density of questing Ixodes ricinus nymphs and adults infected by Borrelia burgdorferi (sensu lato) in Switzerland: spatiotemporal pattern at a regional scale. Vector Borne Zoonotic Dis. 2004;4(1): $23-32$. 
16. Hansford KM, Fonville M, Gillingham EL, Coipan EC, Pietzsch ME, Krawczyk Al, et al. Ticks and Borrelia in urban and peri-urban green space habitats in a city in southern England. Ticks Tick Borne Dis. 2017:8(3):353-61.

17. Kiewra D, Stanczak J, Richter M. Ixodes ricinus ticks (Acari, Ixodidae) as a vector of Borrelia burgdorferi (sensu lato) and Borrelia miyamotoi in Lower Silesia, Poland - preliminary study. Ticks Tick Borne Dis. 2014;5(6):892-7.

18. Krause PJ, Fish D, Narasimhan S, Barbour AG. Borrelia miyamotoi infection in nature and in humans. Clin Microbiol Infect. 2015;21(7):631-9.

19. Platonov AE, Karan LS, Kolyasnikova NM, Makhneva NA, Toporkova MG, Maleev W, et al. Humans infected with relapsing fever spirochete Borrelia miyamotoi, Russia. Emerg Infect Dis. 2011;17(10):1816-23.

20. Reis C, Cote M, Paul RE, Bonnet S. Questing ticks in suburban forest are infected by at least six tick-borne pathogens. Vector Borne Zoonotic Dis. 2011;11(7):907-16.

21. Lommano E, Dvorak C, Vallotton L, Jenni L, Gern L. Tick-borne pathogens in ticks collected from breeding and migratory birds in Switzerland. Ticks Tick Borne Dis. 2014;5(6):871-82.

22. Rollend L, Fish D, Childs JE. Transovarial transmission of Borrelia spirochetes by Ixodes scapularis: a summary of the literature and recent observations. Ticks Tick Borne Dis. 2013;4(1-2):46-51.

23. Wagemakers A, Jahfari S, de Wever B, Spanjaard L, Starink MV, de Vries HJ, et al. Borrelia miyamotoi in vectors and hosts in The Netherlands. Ticks Tick Borne Dis. 2017:8(3):370-4.

24. Blanco JR, Oteo JA. Rickettsiosis in Europe. Ann NY Acad Sci. 2006;1078:26-33.

25. Parola P, Paddock CD, Socolovschi C, Labruna MB, Mediannikov O, Kernif T, et al. Update on tick-borne rickettsioses around the world: a geographic approach. Clin Microbiol Rev. 2013;26(4):657-702.

26. Boretti FS, Perreten A, Meli ML, Cattori V, Willi B, Wengi N, et al. Molecular Investigations of Rickettsia helvetica infection in dogs, foxes, humans, and Ixodes ticks. Appl Environ Microbiol. 2009;75(10):3230-7.

27. Lommano E, Bertaiola L, Dupasquier C, Gern L. Infections and coinfections of questing lxodes ricinus ticks by emerging zoonotic pathogens in western Switzerland. Appl Environ Microbiol. 2012;78(13):4606-12.

28. Fournier PE, Allombert C, Supputamongkol Y, Caruso G, Brouqui P, Raoult D. Aneruptive fever associated with antibodies to Rickettsia helvetica in Europe and Thailand. J Clin Microbiol. 2004;42(2):816-8.

29. Jado I, Oteo JA, Aldamiz M, Gil H, Escudero R, Ibarra V, et al. Rickettsia monacensis and human disease, Spain. Emerg Infect Dis. 2007;13(9):1405-7.

30. Overzier E, Pfister K, Thiel C, Herb I, Mahling M, Silaghi C. Diversity of Babesia and Rickettsia species in questing Ixodes ricinus: a longitudinal study in urban, pasture, and natural habitats. Vector Borne Zoonotic Dis. 2013;13(8):559-64

31. Silaghi C, Hamel D, Thiel C, Pfister K, Pfeffer M. Spotted fever group rickettsiae in ticks, Germany. Emerg Infect Dis. 2011;17(5):890-2.

32. Sprong $H$, Wielinga PR, Fonville $M$, Reusken $C$, Brandenburg AH, Borgsteede $F$, et al. Ixodes ricinus ticks are reservoir hosts for Rickettsia helvetica and potentially carry flea-borne Rickettsia species. Parasit Vectors. 2009;2(1):41.

33. Schorn S, Pfister K, Reulen H, Mahling M, Silaghi C. Occurrence of Babesia spp., Rickettsia spp. and Bartonella spp. in Ixodes ricinus in Bavarian public parks, Germany. Parasit Vectors. 2011;4:135.

34. Špitalská E, Boldiš V, Derdáková M, Selyemová D, Rusnáková Taragelová V. Rickettsial infection in Ixodes ricinus ticks in urban and natural habitats of Slovakia. Ticks Tick Borne Dis. 2014;5(2):161-5.

35. Foggie A. Studies on the infectious agent of tick-borne fever in sheep. J Pathol Bacteriol. 1951:63(1):1-15.

36. Stuen $\mathrm{S}$, Granquist EG, Silaghi C. Anaplasma phagocytophilum - a widespread multi-host pathogen with highly adaptive strategies. Front Cell Infect Microbiol. 2013;3(31)

37. Bakken JS, Dumler JS. Clinical diagnosis and treatment of human granulocytotropic anaplasmosis. Ann NY Acad Sci. 2006;1078:236-47.

38. Bakken JS, Dumler JS, Chen SM, Eckman MR, Van Etta LL, Walker DH. Human granulocytic ehrlichiosis in the upper Midwest United States. A new species emerging? Jama. 1994;272(3):212-8.

39. Dumler JS, Madigan JE, Pusterla N, Bakken JS. Ehrlichioses in humans: epidemiology, clinical presentation, diagnosis, and treatment. Clin Infect Dis. 2007:15(45):S45-51.

40. Ogden NH, Bown K, Horrocks BK, Woldehiwet Z, Bennett M. Granulocytic Ehrlichia infection in ixodid ticks and mammals in woodlands and uplands of the U.K. Med Vet Entomol. 1998;12(4):423-9.

41. Glatz M, Mullegger RR, Maurer F, Fingerle V, Achermann Y, Wilske B, Bloemberg GV. Detection of "Candidatus Neoehrlichia mikurensis", Borrelia burgdorferi (sensu lato) genospecies and Anaplasma phagocytophilum in a tick population from Austria. Ticks Tick Borne Dis. 2014;5(2):139-44.

42. Derdáková M, Václav R, Pangrácova-Blaňarová L, Selyemová D, Koči J, Walder G, Špitalská E. "Candidatus Neoehrlichia mikurensis" and its cocirculation with Anaplasma phagocytophilum in Ixodes ricinus ticks across ecologically different habitats of central Europe. Parasit Vectors. 2014;7:160.

43. Hornok S, Meli ML, Gonczi E, Halasz E, Takacs N, Farkas R, HofmannLehmann R. Occurrence of ticks and prevalence of Anaplasma phagocytophilum and Borrelia burgdorferi s.l. in three types of urban biotopes: forests, parks and cemeteries. Ticks Tick Borne Dis. 2014;5(6):785-9.

44. Pangrácova L, Derdáková M, Pekárik L, Hviščová I, Vichová B, Stanko M, et al. Ixodes ricinus abundance and its infection with the tick-borne pathogens in urban and suburban areas of Eastern Slovakia. Parasit Vectors. 2013;6:238.

45. Andersson M, Zaghdoudi-Allan N, Tamba P, Stefanache M, Chitimia L. Coinfection with 'Candidatus Neoehrlichia mikurensis' and Borrelia afzelii in an Ixodes ricinus tick that has bitten a human in Romania. Ticks Tick Borne Dis. 2014;5(6):706-8.

46. Michelet L, Delannoy S, Devillers E, Umhang G, Aspan A, Juremalm M, et al. High-throughput screening of tick-borne pathogens in Europe. Front Cell Infect Microbiol. 2014;4:103.

47. Moniuszko A, Dunaj J, Czupryna P, Zajkowska J, Pancewicz S. Neoehrlichiosis - a new tick-borne disease - is there a threat in Poland? Przegl Epidemiol. 2015;69(1):23-6.

48. Richter D, Matuschka FR. "Candidatus Neoehrlichia mikurensis", Anaplasma phagocytophilum, and Lyme disease spirochetes in questing european vector ticks and in feeding ticks removed from people. J Clin Microbiol. 2012:50(3):943-7.

49. Burri C, Schumann O, Schumann C, Gern L. Are Apodemus spp. mice and Myodes glareolus reservoirs for Borrelia miyamotoi, "Candidatus Neoehrlichia mikurensis", Rickettsia helvetica, R. monacensis and Anaplasma phagocytophilum? Ticks Tick Borne Dis. 2014;5(3):245-51.

50. Jahfari S, Fonville M, Hengeveld P, Reusken C, Scholte EJ, Takken W, et al. Prevalence of Neoehrlichia mikurensis in ticks and rodents from north-west Europe. Parasit Vectors. 2012;5:74.

51. Silaghi C, Woll D, Mahling M, Pfister K, Pfeffer M. "Candidatus Neoehrlichia mikurensis" in rodents in an area with sympatric existence of the hard ticks Ixodes ricinus and Dermacentor reticulatus, Germany. Parasit Vectors. 2012;5:285.

52. Vayssier-Taussat M, Le Rhun D, Buffet JP, Maaoui N, Galan M, Guivier E, et al. "Candidatus Neoehrlichia mikurensis" in bank voles, France. Emerg Infect Dis. 2012;18(12):2063-5.

53. Svitálkova ZH, Haruštiaková D, Mahríková L, Mojšová M, Berthová L, Slovak M, et al. "Candidatus Neoehrlichia mikurensis" in ticks and rodents from urban and natural habitats of south-western Slovakia. Parasit Vectors. 2016;9:2.

54. Fehr JS, Bloemberg GV, Ritter C, Hombach M, Luscher TF, Weber R, Keller PM. Septicemia caused by tick-borne bacterial pathogen "Candidatus Neoehrlichia mikurensis". Emerg Infect Dis. 2010;16(7):1127-9.

55. Li H, Jiang JF, Liu W, Zheng YC, Huo QB, Tang K, et al. Human infection with "Candidatus Neoehrlichia mikurensis", China. Emerg Infect Dis. 2012;18(10):1636-9.

56. von Loewenich FD, Geissdorfer W, Disque C, Matten J, Schett G, Sakka SG, Bogdan C. Detection of "Candidatus Neoehrlichia mikurensis" in two patients with severe febrile illnesses: evidence for a European sequence variant. J Clin Microbiol. 2010;48(7):2630-5.

57. Welinder-Olsson C, Kjellin E, Vaht K, Jacobsson S, Wenneras C. First case of human "Candidatus Neoehrlichia mikurensis" infection in a febrile patient with chronic lymphocytic leukemia. J Clin Microbiol. 2010;48(5):1956-9.

58. Hunfeld KP, Hildebrandt A, Gray JS. Babesiosis: recent insights into an ancient disease. Int J Parasitol. 2008;38(11):1219-37.

59. Martinot M, Zadeh MM, Hansmann Y, Grawey I, Christmann D, Aguillon S, et al. Babesiosis in immunocompetent patients, Europe. Emerg Infect Dis. 2011; 17(1):114-6.

60. Gigandet L, Stauffer E, Douet V, Rais O, Moret J, Gern L. Prevalence of three zoonotic Babesia species in Ixodes ricinus (Linné, 1758) nymphs in a suburban forest in Switzerland. Vector Borne Zoonotic Dis. 2011;11(4):363-6.

61. Hartelt K, Oehme R, Frank H, Brockmann SO, Hassler D, Kimmig P. Pathogens and symbionts in ticks: prevalence of Anaplasma phagocytophilum (Ehrlichia sp.), Wolbachia sp., Rickettsia sp., and Babesia sp. in southern Germany. Int J Med Microbiol. 2004;37:86-92.

62. Skotarczak B, Cichocka A. Isolation and amplification by polymerase chain reaction DNA of Babesia microti and Babesia divergens in ticks in Poland. Ann Agric Environ Med. 2001;8(2):187-9. 
63. Silaghi C, Woll D, Hamel D, Pfister K, Mahling M, Pfeffer M. Babesia spp. and Anaplasma phagocytophilum in questing ticks, ticks parasitizing rodents and the parasitized rodents - analyzing the host-pathogen-vector interface in a metropolitan area. Parasit Vectors. 2012;5:191.

64. Hamšiková Z, Kazimírová M, Haruštiaková D, Mahríková L, Slovák M, Berthová L, et al. Babesia spp. in ticks and wildlife in different habitat types of Slovakia. Parasit Vectors. 2016;9:291

65. Stanczak J, Cieniuch S, Lass A, Biernat B, Racewicz M. Detection and quantification of Anaplasma phagocytophilum and Babesia spp. in Ixodes ricinus ticks from urban and rural environment, northern Poland, by realtime polymerase chain reaction. Exp Appl Acarol. 2015;66(1):63-81.

66. Chauvin A, Moreau E, Bonnet S, Plantard O, Malandrin L. Babesia and its hosts: adaptation to long-lasting interactions as a way to achieve efficient transmission. Vet Res. 2009;40(2):21.

67. Gray J, von Stedingk LV, Gurtelschmid M, Granstrom M. Transmission studies of Babesia microti in Ixodes ricinus ticks and gerbils. J Clin Microbiol. 2002; 40(4):1259-63.

68. Casati S, Sager H, Gern L, Piffaretti JC. Presence of potentially pathogenic Babesia sp. for human in Ixodes ricinus in Switzerland. Ann Agric Environ Med. 2006;13(1):65-70

69. Rieille N, Bressanelli S, Freire CC, Arcioni S, Gern L, Péter O, Voordouw MJ. Prevalence and phylogenetic analysis of tick-borne encephalitis virus (TBEV) in field-collected ticks (Ixodes ricinus) in southern Switzerland. Parasit Vectors. 2014;7:443.

70. Lommano E, Burri C, Maeder G, Guerne M, Bastic V, Patalas E, Gern L. Prevalence and genotyping of tick-borne encephalitis virus in questing Ixodes ricinus ticks in a new endemic area in western Switzerland. J Med Entomol. 2012;49(1):156-64.

71. Burri C, Moran Cadenas F, Douet V, Moret J, Gern L. Ixodes ricinus density and infection prevalence of Borrelia burgdorferi (sensu lato) along a Northfacing altitudinal gradient in the Rhone Valley (Switzerland). Vector Borne Zoonotic Dis. 2007;7(1):50-58.

72. Jouda F, Perret JL, Gern L. Ixodes ricinus density, and distribution and prevalence of Borrelia burgdorferi (sensu lato) infection along an altitudinal gradient. J Med Entomol. 2004;41(2):162-9.

73. Pilloux L, Aeby S, Gaumann R, Burri C, Beuret C, Greub G. The high prevalence and diversity of Chlamydiales DNA within Ixodes ricinus ticks suggest a role for ticks as reservoirs and vectors of Chlamydia-related bacteria. Appl Environ Microbiol. 2015;81(23):8177-82.

74. Cathomas F. Vorkommen von Ixodes ricinus und Borrelia burgdorferi (sensu lato) in städtischen Naherholungsgebieten am Beispiel von Basel (Schweiz). Mitt Naturforsch Ges Basel. 2005:8:63-79.

75. University of Bristol Online Photographic Guide to Ticks, Bristol University tick ID [http://www.bristoluniversitytickid.uk//. Accessed July 2016.

76. Hillyard P. Ticks of North-West Europe Synopses of the British Fauna, No. 52. London: The Linnean Society of London; 1996.

77. Phylogeny.fr webpage. [http://phylogeny.lirmm.fr/phylo_cgi/index.cgi]. Accessed Oct 2016.

78. Altschul SF, Madden TL, Schaffer AA, Zhang J, Zhang Z, Miller W, Lipman DJ, Gapped BLAST. PSI-BLAST: a new generation of protein database search programs. Nucleic Acids Res. 1997;25(17):3389-402

79. NCBI Nucleotide database [https://www.ncbi.n/m.nih.gov/nucleotide/]. Accessed 02. Dec 2016.

80. Alekseev AN, Dubinina HV, Van De Pol I, Schouls LM. Identification of Ehrlichia spp. and Borrelia burgdorferi in Ixodes ticks in the Baltic regions of Russia. J Clin Microbiol. 2001;39(6):2237-42.

81. Poupon M-A, Lommano E, Humair PF, Douet V, Rais O, Schaad M, et al. Prevalence of Borrelia burgdorferi (sensu lato) in ticks collected from migratory birds in Switzerland. Appl Environ Microbiol. 2006;72(1):976-9.

82. Rijpkema SG, Molkenboer MJ, Schouls LM, Jongejan F, Schellekens JF. Simultaneous detection and genotyping of three genomic groups of Borrelia burgdorferi (sensu lato) in Dutch Ixodes ricinus ticks by characterization of the amplified intergenic spacer region between $5 \mathrm{~S}$ and 235 rRNA genes. J Clin Microbiol. 1995;33(12):3091-5.

83. Gern L, Douet V, Lopez Z, Rais O, Cadenas FM. Diversity of Borrelia genospecies in Ixodes ricinus ticks in a Lyme borreliosis endemic area in Switzerland identified by using new probes for reverse line blotting. Ticks Tick Borne Dis. 2010;1(1):23-9.

84. R Development Core Team R: A language and environment for statistical computing. Vienna, Austria, 2008.
85. Sassera D, Beninati T, Bandi C, Bouman EA, Sacchi L, Fabbi M, Lo N. Candidatus Midichloria mitochondrii', an endosymbiont of the tick Ixodes ricinus with a unique intramitochondrial lifestyle. Int J Syst Evol Microbiol. 2006:56(Pt 11):2535-40.

86. Pfaffle M, Littwin N, Muders SV, Petney TN. The ecology of tick-borne diseases. Int J Parasitol. 2013:43(12-13):1059-77.

87. Perez D, Kneubuhler Y, Rais O, Gern L. Seasonality of Ixodes ricinus ticks on vegetation and on rodents and Borrelia burgdorferi (sensu lato) genospecies diversity in two Lyme borreliosis-endemic areas in Switzerland. Vector Borne Zoonotic Dis. 2012;12(8):633-44.

88. Drelich A, Andreassen A, Vainio K, Kruszynski P, Wasik TJ. Prevalence of tickborne encephalitis virus in a highly urbanized and low risk area in southern Poland. Ticks Tick Borne Dis. 2014;5(6):663-7.

89. Mehlhorn H, Mehlhorn T, Muller M, Vogt M, Rissland J. Tick survey for prevalent pathogens in peri-urban recreation sites in Saarland and Rhineland-Palatinate (Germany). Parasitol Res. 2016;115(3):1167-72.

90. Corrain R, Drigo M, Fenati M, Menandro ML, Mondin A, Pasotto D, Martini M. Study on ticks and tick-borne zoonoses in public parks in Italy. Zoonoses Public Health. 2012;59(7):468-76.

91. Kahl O, Schmidt K, Schonberg A, Laukamm-Josten U, Knulle W, Bienzle U. Prevalence of Borrelia burgdorferi in Ixodes ricinus ticks in Berlin (West). Zentralbl Bakteriol Mikrobiol Hyg A. 1989;270(3):434-40.

92. Maetzel D, Maier WA, Kampen H. Borrelia burgdorferi infection prevalences in questing Ixodes ricinus ticks (Acari: Ixodidae) in urban and suburban Bonn, western Germany. Parasitol Res. 2005;95(1):5-12.

93. Burri C, Dupasquier C, Bastic V, Gern L. Pathogens of emerging tick-borne diseases, Anaplasma phagocytophilum, Rickettsia spp., and Babesia spp., in Ixodes ticks collected from rodents at four sites in Switzerland (Canton of Bern). Vector Borne Zoonotic Dis. 2011;11(7):939-44.

94. Leutenegger CM, Pusterla N, Mislin CN, Weber R, Lutz H. Molecular evidence of coinfection of ticks with Borrelia burgdorferi (sensu lato) and the human granulocytic ehrlichiosis agent in Switzerland. J Clin Microbiol. 1999;37(10):3390-1.

95. Liz JS, Anderes L, Sumner JW, Massung RF, Gern L, Rutti B, Brossard MPCR. detection of granulocytic ehrlichiae in Ixodes ricinus ticks and wild small mammals in western Switzerland. J Clin Microbiol. 2000;38(3):1002-7.

96. Pusterla N, Leutenegger CM, Huder JB, Weber R, Braun U, Lutz H. Evidence of the human granulocytic ehrlichiosis agent in Ixodes ricinus ticks in Switzerland. J Clin Microbiol. 1999;37(5):1332-4.

97. Wicki R, Sauter P, Mettler C, Natsch A, Enzler T, Pusterla N, et al. Swiss Army Survey in Switzerland to determine the prevalence of Francisella tularensis, members of the Ehrlichia phagocytophila genogroup, Borrelia burgdorferi (sensu lato), and tick-borne encephalitis virus in ticks. Eur J Clin Microbiol Infect Dis. 2000;19(6):427-32.

98. Brouqui P, Dumler JS, Lienhard R, Brossard M, Raoult D. Human granulocytic ehrlichiosis in Europe. Lancet. 1995;346(8977):782-3.

99. Maurer FP, Keller PM, Beuret C, Joha C, Achermann Y, Gubler J, et al. Close geographic association of human neoehrlichiosis and tick populations carrying "Candidatus Neoehrlichia mikurensis" in eastern Switzerland. J Clin Microbiol. 2013;51(1):169-76.

100. Hildebrandt A, Gray JS, Hunfeld KP. Human babesiosis in Europe: what clinicians need to know. Infection. 2013;41(6):1057-72.

101. Moutailler S, Valiente Moro C, Vaumourin E, Michelet L, Tran FH, Devillers E, et al. Co-infection of ticks: The rule rather than the exception. PLoS Negl Trop Dis. 2016;10(3)

102. Diuk-Wasser MA, Vannier E, Krause PJ. Coinfection by Ixodes tick-borne pathogens: Ecological, epidemiological, and clinical consequences. Trends Parasitol. 2016;32(1):30-42.

103. Tijsse-Klasen E, Sprong H, Pandak N. Co-infection of Borrelia burgdorferi (sensu lato) and Rickettsia species in ticks and in an erythema migrans patient. Parasit Vectors. 2013;6:347.

104. Horowitz HW, Aguero-Rosenfeld ME, Holmgren D, McKenna D, Schwartz I, Cox ME, Wormser GP. Lyme disease and human granulocytic anaplasmosis coinfection: impact of case definition on coinfection rates and illness severity. Clin Infect Dis. 2013;56(1):93-9.

105. Andersson M, Raberg L. Wild rodents and novel human pathogen "Candidatus Neoehrlichia mikurensis", southern Sweden. Emerg Infect Dis. 2011;17(9):1716-8

106. Gern L, Lienhard R, Peter O. Diseases and pathogenic agents transmitted by ticks in Switzerland. Rev Med Suisse. 2010;6(266):1906-9. (In French) 
107. Lo N, Beninati T, Sassera D, Bouman EA, Santagati S, Gern L, et al. Widespread distribution and high prevalence of an alpha-proteobacterial symbiont in the tick Ixodes ricinus. Environ Microbiol. 2006;8(7):1280-7.

108. Courtney JW, Kostelnik LM, Zeidner NS, Massung RF. Multiplex real-time PCR for detection of Anaplasma phagocytophilum and Borrelia burgdorferi. I Clin Microbiol. 2004;42(7):3164-8.

109. Teal AE, Habura A, Ennis J, Keithly JS, Madison-Antenucci SA. New real-time PCR assay for improved detection of the parasite Babesia microti. J Clin Microbiol. 2012;50(3):903-8.

110. Ornstein K, Barbour AGA. reverse transcriptase-polymerase chain reaction assay of Borrelia burgdorferi $16 \mathrm{~S}$ rRNA for highly sensitive quantification of pathogen load in a vector. Vector Borne Zoonotic Dis. 2006;6(1):103-12.

111. Coipan EC, Fonville M, Tijsse-Klasen E, van der Giessen JW, Takken W, Sprong H, Takumi K. Geodemographic analysis of Borrelia burgdorferi (sensu lato) using the 5S-23S rDNA spacer region. Infect Genet Evol. 2013;17:216-22.

112. Najm NA, Meyer-Kayser E, Hoffmann L, Herb I, Fensterer V, Pfister K, Silaghi CA. molecular survey of Babesia spp. and Theileria spp. in red foxes (Vulpes vulpes) and their ticks from Thuringia, Germany. Ticks Tick Borne Dis. 2014; 5(4):386-91.

113. Jado I, Escudero R, Gil H, Jimenez-Alonso Ml, Sousa R, Garcia-Perez AL, et al. Molecular method for identification of Rickettsia species in clinical and environmental samples. J Clin Microbiol. 2006:44(12):4572-6.

114. Rothen J, Githaka N, Kanduma EG, Olds C, Pfluger V, Mwaura S, et al. Matrixassisted laser desorption/ionization time of flight mass spectrometry for comprehensive indexing of East African ixodid tick species. Parasit Vectors. 2016;9:151.

\section{Submit your next manuscript to BioMed Central and we will help you at every step:}

- We accept pre-submission inquiries

- Our selector tool helps you to find the most relevant journal

- We provide round the clock customer support

- Convenient online submission

- Thorough peer review

- Inclusion in PubMed and all major indexing services

- Maximum visibility for your research

Submit your manuscript at www.biomedcentral.com/submit 